\title{
The on-line processing of unaccusativity in Greek agrammatism
}

Article

Published Version

Peristeri, E., Tsimpli, I.-M. and Tsapkini, K. (2013) The on-line processing of unaccusativity in Greek agrammatism. Applied Psycholinguistics, 34 (2). pp. 233-276. ISSN 1469-1817 doi: https://doi.org/10.1017/S0142716411000683 Available at https://centaur.reading.ac.uk/31233/

It is advisable to refer to the publisher's version if you intend to cite from the work. See Guidance on citing.

To link to this article DOI: http://dx.doi.org/10.1017/S0142716411000683

Publisher: Cambridge University Press

All outputs in CentAUR are protected by Intellectual Property Rights law, including copyright law. Copyright and IPR is retained by the creators or other copyright holders. Terms and conditions for use of this material are defined in the End User Agreement.

\section{www.reading.ac.uk/centaur}

\section{CentAUR}

Central Archive at the University of Reading

Reading's research outputs online 


\title{
The on-line processing of unaccusativity in Greek agrammatism
}

\author{
ELENI PERISTERI and IANTHI-MARIA TSIMPLI \\ Aristotle University of Thesaloniki
}

KYRANA TSAPKINI

John Hopkins University

Received: September 25, 2009 Accepted for publication: March 7, 2011

\section{ADDRESS FOR CORRESPONDENCE}

Eleni Peristeri, Aristotle University of Thesaloniki, School of English, Ethnikis Aminis, P. C. 54 124, Office 308A, Thessaloniki, Greece. E-mail: eperiste@enl.auth.gr

\begin{abstract}
We investigated the on-line processing of unaccusative and unergative sentences in a group of eight Greek-speaking individuals diagnosed with Broca aphasia and a group of language-unimpaired subjects used as the baseline. The processing of unaccusativity refers to the reactivation of the postverbal trace by retrieving the mnemonic representation of the verb's syntactically defined antecedent provided in the early part of the sentence. Our results demonstrate that the Broca group showed selective reactivation of the antecedent for the unaccusatives. We consider several interpretations for our data, including explanations focusing on the transitivization properties of nonactive and active voice-alternating unaccusatives, the costly procedure claimed to underlie the parsing of active nonvoice-alternating unaccusatives, and the animacy of the antecedent modulating the syntactic choices of the patients.
\end{abstract}

Much previous research on sentence comprehension in aphasia has shown that agrammatic individuals with aphasia have difficulty understanding sentences with movement. In particular, they have difficulty understanding sentences in which arguments do not appear in their canonical order, as in the unaccusative structure in (1):

(1) The ice-cream $i$ melted $i$

The unaccusativity hypothesis claims that there is a trace in the syntactic representation of the sentence, occupying the postverbal position, which is ultimately co-indexed with the "ice-cream," thus leading to a noncanonical interpretation of the sentence (i.e., the theme moves to a syntactic subject position typically occupied by an agent; Perlmutter, 1978). In comprehending unaccusative sentences, it is the language processor's task to identify the gap or trace associated with the moved object and resolve the movement relationship, which is also called 
Peristeri et al.: The time course of antecedent reactivation

filler-gap dependency (Burzio, 1986; Friedmann, Taranto, Shapiro, \& Swinney, 2008; Perlmutter, 1978).

The sentence processing experiments have typically used different sentence types as a means to examine underlying operations in agrammatic processing (Grodzinsky, 1990; Grodzinsky, 1995; Grodzinsky, Piñango, Zurif, \& Drai, 1999; Hagiwara, 1993; Swinney, Zurif, Prather, \& Love, 1996; Zurif, Swinney, Prather, Solomon, \& Bushell, 1993). The common goal has been to illuminate processes underlying language-unimpaired comprehension and how these go awry in aphasia. The outcome of the overwhelming majority of these studies was that their subjects with Broca aphasia do not reliably understand sentences with displaced determiner phrases (DPs), or perhaps more generally, sentences that require the computation of (especially, long-distance) dependencies.

Even though the effect of filler-gap dependencies on on-line sentence interpretation has attracted a growing amount of interest within the aphasiological community over recent years, there have been relatively a few studies which have specifically examined the real-time operations relevant to the gap-filling process in aphasia (Blumstein et al., 1998; Burkhardt, Piñango, \& Wong, 2003; Love, Swinney, \& Zurif, 2001; Swinney et al., 1996; Zurif et al., 1993). Up to now, one of the methods which have been extensively used to examine the real-time processing of sentences with movement in aphasia is lexical priming. In the crossmodal lexical priming (CMLP) task, subjects listen to a sentence and make a lexical decision about a word presented visually at a position in the ongoing sentence. The CMLP technique is based on the idea that the speed of access to a word during sentence processing is affected by semantic priming; an item, or crucially a reactivated item at the position of its trace, primes a semantically related word, such that the reaction times (RTs) to a visually presented word that is related to a word in the sentence will be shorter relative to a visually presented word that is unrelated to the words of the sentence. There have been a number of experimental investigations with unimpaired populations that have come to support the view that the linkage between an antecedent filler and a gap is one that is made immediately upon discovery of the "gap" site (e.g., Love \& Swinney, 1996; Nagel, Shapiro, \& Nawy, 1994; Swinney, Ford, Frauenfelder, \& Bresnan, 1987).

The studies which have examined the on-line processing of sentences with movement in aphasia by employing the CMLP technique yielded interesting but conflicting results. In their study, Zurif et al. (1993) have investigated Broca and Wernicke patients' ability to form in real-time intrasentential dependency relations in subject-relative clauses by testing for priming for the relative pronoun at the position of the trace (i.e., after the pronoun) and at a position before the trace (pregap site). According to the findings, the neurologically intact and the Wernicke aphasic subjects showed priming (i.e., relative facilitation in lexical decision for words related to the antecedents) at gap sites but not at pregap sites. By contrast, the Broca patients did not show priming at either position. Swinney and colleagues (1987; following up similar results from Zurif et al., 1993) had examined Broca and Wernicke aphasic individuals' performance in a CMLP priming task with object relative clauses. For participants with Wernicke aphasia, Swinney et al. (1996) found evidence of reactivation at the trace site, such that there was reliable priming of words related to the head DP after the verb but not before. In contrast, 
they found that participants with Broca aphasia showed no reliable priming in either position. Both studies' similar findings were accounted for in terms of an overall slowed processing account of aphasic comprehension preventing the Broca patients either from locating the antecedent in time or from accessing momentarily all of the possible argument structure configurations within a verb's lexical entry.

A later study from Blumstein and colleagues (1998) essentially contradicted the Swinney-Zurif (Swinney et al., 1996; Zurif et al., 1993) results. Blumstein and colleagues repeated the Swinney et al. (1996) studyusing purely auditory materials (i.e., the target word was presented in the voice of a speaker of the opposite sex from the speaker of the sentence). An additional difference from the Swinney-Zurif studies is that probe words were presented at only one position (the site where the gap was licensed) and both relative clauses and wh-questions were used. Blumstein et al. found priming for words semantically related to the antecedent of a trace for Broca aphasic and elderly groups, but no priming for words separated from a prime by an equal number of syllables in control sentences without traces. Moreover, there was no evidence in favor of a priming effect at the trace site for Wernicke aphasic participants with any sentence type, also the opposite result from that reported by Swinney and colleagues (1996).

The inconsistency of the results of the aforementioned studies has been mainly attributed to the distinct methodological designs used in each of them. Balogh et al. (1998) argued that the priming effect observed at the single probe position available in Blumstein et al.'s (1998) study may reflect end of sentence "wrap up" reactivation of previously presented lexical items, not syntactically based coindexation of traces due to structural factors. In addition, the materials used by Swinney and colleagues (1996) are subject to another concern raised by McKoon and Ratcliff (1994). They argue that the priming effects found with these materials may be due to a better pragmatic fit of the related rather than the unrelated words to the pragmatic context at the point of the trace, not to the co-indexation of the trace per se. Finally, Zurif et al.'s (1993) results must be tempered by the consideration that their Broca aphasic participants did not show evidence in favor of a priming effect at the pregap site. Such findings may reflect slowed lexical access processes, further implicating the possibility that Broca patients would have shown priming of the moved element had they been tested far enough downstream from the trace site (Love et al., 2001; Swinney et al., 1996). The CMLP technique then requires a design that would be sensitive to the temporal evanescence of aurally presented sentences, in case antecedent reactivation takes place at a point later than its syntactic licensing.

The latter possibility was successfully integrated in the CMLP design of Burkhardt, Pinango, and Wong's (2003) study that has investigated the on-line processing of unergative and unaccusative verbs with two English-speaking agrammatic patients and a control group. According to the analyses of the subjects' response times in the unaccusative verbs, the aphasic patients failed to reactivate the antecedent at the point of the trace; yet, their parser did show priming for the antecedent on average $150 \mathrm{~ms}$ later than the language unimpaired subjects who provided evidence of antecedent reactivation not immediately at the postverbal trace position but at a significantly later point in time $(650 \mathrm{~ms}$ after the unaccusative verb). The researchers have attributed such pattern of performance to the 
Peristeri et al.: The time course of antecedent reactivation

slow syntax hypothesis according to which Broca patients' syntactic knowledge and ability to establish the dependency relation between the antecedent and its trace in unaccusative verbs is spared, yet delayed syntactic structure formation caused by the anterior lesions to the patients' left hemisphere prevented them from responding on time. In contrast, no antecedent reactivation pattern was observed for the unergative verb class for the two patients. Two further points worth mentioning from Burkhardt et al.'s (2003) study is that (a) no clear pattern of priming effect for the antecedent was shown by Broca patients when tested on unaccusatives lacking a causative counterpart ${ }^{1}$ in contrast to the control subjects who showed the same reactivation pattern across all unaccusative sentences, and (b) the neurologically intact control subjects have shown a statistically significant priming effect immediately after the verb in the unergative verb class. The specific finding was accounted for by the authors in terms of the verb phrase (VP)-internal subject hypothesis (Koopman \& Sportiche, 1991, among others), which claims that the subject DP originates in a VP-internal position (more specifically, the [Spec, VP]), from which it raises into [Spec, inflection phrase] in English leaving behind a trace. Burkhardt et al. hold the postverbal subject trace responsible for the priming effect registered within the short time window of $100 \mathrm{~ms}$ after the unergative verb has been heard.

Although there is little consensus among the studies regarding the modeling of the CMLP technique so that it would best capture aphasic comprehension of sentences involving movement, they appear to be similar in claiming that some operation relevant to the gap-filling process in Broca patients is greatly slowed and error prone. The specific processing approach suggests that syntactic operations are time sensitive and temporally unforgiving; computing a dependency relation must occur at the right time in the processing stream or else comprehension will suffer. Either the slow processing account takes the form of a delay in syntactic structure formation in Broca aphasia (Burkhardt et al., 2003; Haarmann \& Kolk, 1991) or the form of protracted lexical access capacities limiting the patients' ability to fill the gap at the point where it is properly licensed in the syntax (Love et al., 2008; Swinney et al., 1996), the processing outcome for individuals with Broca aphasia will be the same: slowed processing routines will create problems for locating and successfully reactivating an antecedent for a trace in a fillergap dependency. Delayed application of the processing routines implicated in the resolution of filler-gap dependencies in Broca aphasia has also been shown with a cross-modal lexical decision task testing reflexive-antecedent dependencies (Burkhardt, Avrutin, Piñango, \& Ruigendijk, 2008), as well as an anomaly detection task testing filler-gap dependencies in object relative clauses (Dickey \& Thompson, 2004). Likewise, Love et al. (2008) report evidence suggesting that for complex object-relative clauses, aphasic participants showed evidence of significantly delayed gap filling in a CMLP paradigm.

The overall slowed processing account of aphasic comprehension contrasts with other accounts of aphasic performance in that it postulates no deficits in aphasic syntactic representations (see trace deletion hypothesis in Grodzinsky, 1990, 1995, 2000) or in the processes responsible for mapping those representations onto an interpretation (see Linebarger, Schwartz, \& Saffran, 1983; Schwartz, Linebarger, Saffran, \& Pate, 1987). Rather, it claims that agrammatic individuals try to 
comprehend sentences with movement more or less as healthy subjects do, but are slower and less efficient in their processing. Under the slow processing model, aphasic individuals' difficulties in understanding sentences with movement are not particularly delayed compared to other comprehension processes: all processing is slowed and inefficient.

\section{CURRENT STUDY}

With this brief background in mind we now present our investigation of the processing of unaccusative sentences in a population of Greek-speaking aphasic patients. As described above, Burkhardt et al.'s (2003) CMLP study has offered evidence supporting the distinct processing of the two verb classes (i.e., unergatives and unaccusatives) by two Broca patients, whereas their data spoke in favor of an overall slowing down of "the syntactic structure building (i.e., Merge) operations" (Burkhardt et al., 2003, p. 20) through which the dependency relation between the derived DP subject and the postverbal trace is instantiated in unaccusative verbs.

In the present study, we also applied the CMLP technique, albeit with some modifications in the experimental population and the experimental stimuli. First, we ran the experiment with a group of eight Greek-speaking agrammatic patients in the hope of gaining robust and reliable data on the on-line processing of unaccusative (vs. unergative) verbs by Broca patients. Second, the morphological realization of unaccusativity in Greek was also fully manipulated; as will be described analytically in the linguistic framework of the study, the rich morphological paradigm of unaccusative verbs in Greek is an excellent candidate to tease apart morphological factors that may interfere to influence antecedent reactivation in unaccusative sentence processing from pure syntactic operations, like the reconstruction of the antecedent in postverbal position. The realization of some Greek unaccusative verbs with nonactive (NACT) voice morphology, as well as the optional marking of some active (ACT) unaccusative verbs with NACT voice morphology proves a fruitful area to compare the priming effect elicited by morphologically marked (i.e., NACT) verbs with that elicited by morphologically less complex (i.e., ACT) verbal predicates.

In individuals with aphasia, processing disadvantages for morphologically complex words including inflected verbs have been reported (Friederici et al., 1992; Marslen-Wilson \& Tyler, 1997; Miceli \& Caramazza, 1988). Aphasic individuals' inflectional errors appear to support a decompositional view of morphological processing, whereby not only are there distinct neurocognitive mechanisms for the retrieval of verbs and inflections from long-term memory, but there are also specialized neurocognitive mechanisms for combining stems and inflections to yield grammatical forms. A dual system approach has been proposed whereby patient groups with posterior damage were predicted to have an impairment in declarative memory based representations; thus, they were assumed to have difficulty with the computation of irregular but not regular past tense forms for real and novel words, whereas dysfunction of basal ganglia and frontal lobe circuits (as in Broca aphasia) were predicted to affect the procedural brain memory system and, in particular, grammatical rules (Ullman et al., 1997). The regular-irregular dissociation hypothesis has been extensively examined by studies focusing on 
the computation of past tense forms by aphasic agrammatic patients of various language backgrounds (Balaguer et al., 2004; Bird et al., 2003; Penke, Janssen, \& Krause, 1999; Tsapkini, Jarema, \& Kehaya, 2002). Yet, the dual mechanism theory has not been clearly confirmed by neuropsychological data, because aphasic errors have not been restricted to morphology but to semantics and/or phonology as well.

A second potential locus of verb inflection errors in aphasia is syntactic encoding, and more specifically, the complexity of the verb's argument structure. Specifically, unergative verbs were found to be inflected correctly more easily than both two-place and three-place transitive verbs in a picture-naming task (Luzzatti et al., 2002; Thompson, 2003). Unaccusative verbs are rarely produced since they are considered to be syntactically complex, in that their grammatical subjects originate in the postverbal complement position and then move in the subject position. A theoretical account of these results is the argument structure complexity hypothesis (Thompson, 2003), which states that verbs with complex argument structure, both in terms of number of arguments and/or of movement, are impaired in agrammatic production.

Although the bulk of studies to date have focused on aphasic individuals' pronounced production difficulty with morphologically synthetic (inflected) verb forms, including unaccusatives, the present study seeks to investigate whether we should also anticipate such difficulty in comprehension as reflecting the processing of morphologically marked, that is, NACT (vs. morphologically unmarked, i.e., ACT) unaccusative verbs; more specifically, whether NACT voice morphology marking on unaccusative verbs will affect aphasic patients' inclination to anticipate (or not) a postverbal trace as the sentence unfolds.

Finally, we have investigated the effect of the [ \pm animacy] of the syntactic subject of the verbs on the aphasic subjects' ability to disambiguate the meaning of both ACT and NACT unaccusative verbs during on-line sentence processing. We will elaborate on this, and other possibilities offered by the current study, in the Predictions section after the linguistic framework of the study.

\section{THE LINGUISTIC FRAMEWORK OF THE STUDY}

In the present research, we focus on unergative and unaccusative verbs covered by the global term "intransitivity," which is defined in terms of the lack of accusative case licensing by the verb. It is crucial that the distinction between unergatives and unaccusatives relates to the distinct ways in which the syntactic subject of these verbs is derived in syntax. This issue is closely linked to the lexicosemantic structure of intransitive verbs and the way it feeds into the syntactic component in terms of the arguments projected onto the syntactic structure. Fine distinctions related to the semantics of the intransitive verbs depending on whether they include an agent are critical in their syntactic derivation. The defenders of the unaccusativity hypothesis assume that the subject of unergative verbs is merged in its spell-out position and attracts the external theta feature of the Voice ${ }^{\circ}$ head. In contrast, the external argument of unaccusative verbs is unavailable in syntax but present at the level of the conceptual structure of the verbs (Hale \& Keyser, 1993; Levin \& Rappaport-Hovav, 1995). The subjects of unaccusative verbs are base generated 
as internal arguments and subsequently move to [Spec, tense phrase] position to satisfy the extended projection principle.

As mentioned above, an interesting property of unaccusative verbs in Greek is the way in which the suppression of the external theta feature is realized in the morphological component. More specifically, according to the categorization proposed by Alexiadou and Anagnostopoulou (2004, pp. 123-127), there are four classes of unaccusatives in Greek:

In the first class, the unaccusative verbs have NACT morphology, while in their unmarked (i.e., ACT voice form, they are transitive):

(2) O jiatros jiatrepse to Jiani. (causative/transitive)

The-NOM doctor-NOM heal-PERF-ACTIVE.3s the-ACC Jiani-ACC

"The doctor healed John"

(3) O Jianis jiatreftike (apo thavma). (unaccusative)

The-NOM Jianis-NOM heal-PERF-NON-ACTIVE.3s (by miracle-ACC)

"John healed (by a miracle)"

The second class consists of unaccusatives that have NACT morphology. Active voice morphology is used with transitive verbs, but there is also a limited number of verbs that are unergatives with ACT morphology:

(4) O Jianis ekapse ti supa. (causative/transitive)

The-NOM Jianis-NOM burn-PERF-ACTIVE.3s the-ACC soup-ACC

"John burnt the soup"

(5) I supa kaike. (unaccusative)

The-NOM soup-NOM burn-PERF-NON-ACTIVE.3s

"The soup burnt"

(6) I fotia kei/*kejete. (intransitive/unergative)

The-NOM fire-NOM burn-IMPERF-ACTIVE.3s/burn-IMPERF-NON-ACTIVE.3s

"The fire burns"

The verbs in this class are de-adjectival verbs. The unaccusatives have ACT morphology and can only take an inanimate subject. Active morphology is present in transitive variants as well:

(7) O Jianis adiase ti sakula. (causative/transitive)

The-NOM Jianis-NOM empty-PERF-ACTIVE.3s the-ACC bag-ACC

"John emptied the bag"

(8) I sakula adiase. (unaccusative)

The-NOM bag-NOM empty-PERF-ACTIVE.3s

"The bag emptied"

In this class, all of the transitive verbs appear with ACT voice morphology. Unaccusatives optionally appear either with ACT or NACT morphology without the voice change affecting the availability of the unaccusative reading. Such verbs are labeled as "alternating" verbs and they are referred to in Greek as verbs 
Peristeri et al.: The time course of antecedent reactivation

"ditipias"2 (literally of two forms, Theophanopoulou-Kontou, 2000). Henceforth, these verbs will be referred to as "voice-alternating" verbs.

In case the voice-alternating verb in Greek has NACT morphology, its subject may either be animate or inanimate; when the subject is animate the verb's meaning is ambiguous between an unaccusative, a reflexive, and a passive reading:

(9) O Jianis lerose to trapezomadilo. (transitive)

The-NOM Jianis-NOM dirty-PERF-ACTIVE.3s the-ACC tablecloth-ACC

"John dirtied the tablecloth"

(10) To trapezomadilo lerose/lerothike (apo to krasi). (unaccusative)

The-NOM tablecloth-NOM dirty-PERF-ACTIVE.3s/dirty-PERF-NON-ACTIVE.3s (by the-ACC wine-ACC)

"The tablecloth got dirty (from the wine)"

(11) I Maria lerothike (apo tis laspes/moni tis/apo ton Kosta). (unaccusative/ reflexive/passive)

The-NOM Mary-NOM dirty-PERF-NON-ACTIVE.3s (from the-ACC mud-ACC/by herself-NOM/by Kostas-ACC)

"Mary got dirty (from the mud/by herself/by Kostas)"

According to Tsimpli's account of unaccusativity (2006), the realization of ACT or NACT voice morphology on unaccusative verbs in Greek is related to the absence/presence of Voice ${ }^{\circ}$ projection, thus supporting a grammatical interpretation of the phenomenon. In ACT unaccusatives the Voice projection is missing and the transitive alternation is attributed to "a transitivity or agentive feature borne by light v, independently of Voice" (Tsimpli, 2006, p. 26). More specifically, the causative/unaccusative alternation applies to a specific class of externally caused change of state verbs, like spao/"break," klino/“close," and anijo/“open." Change of state verbs with internal cause do not appear to have a causative alternant (e.g., to lulu $i$ anthise/ "the flower blossomed-ACT") *o ilios anthise to lulu $\delta i /$ "*the sun blossomed-ACT the flower" (Levin \& Rappaport-Hovav, 1995; Theophanopoulou-Kontou, 2001). In the latter verbal set, the internal argument is the only argument that is syntactically active and it either moves to [Spec, tense phrase] position to satisfy the extended projection principle or it is directly merged in its spell-out position and attracts the internal theta feature on the Voice $^{\circ}$ head (Manzini \& Roussou, 2000).

With respect to the unaccusative verbs marked with NACT morphology, Tsimpli (2006) argues that the morphological marking is the reflex of the Voice ${ }^{\circ}$ projection. The latter attracts the verb's external theta feature that is left underspecified with regards to its interpretation. The verb's internal feature is attracted by the internal argument that subsequently moves to subject position. Failure of the Voice $^{\circ}$ head to lexicalize the attracted agentive feature forces its interpretation at the LF level where the verb receives its unaccusative reading "depending on the semantics of the verbal predicate (change of state, situation type), and pragmatic information, (i.e., the naturalness, frequency and transparency of the relation between the subject and the event described by the verb"; Tsimpli, 2006, p. 27). This derivation applies to all verbal structures marked with NACT morphology in Greek, including passives 
and middles, ${ }^{3}$ whereas reflexive structures differ in that the subject DP is an agent and both external and internal thematic features are interpreted within the verbal domain. Besides this grammatical distinction characterizing the derivation of the syntactic subject in reflexives and NACT unaccusative verbs, individual lexical preferences and real world knowledge also appear to play a crucial role in the disambiguation between the two verbal structures, especially when the NACT unaccusative verb takes an [+animate] entity in subject position. As can be seen in (12) and (13) below, in the absence of any disambiguating cues provided by the continuation of the clause, the NACT verb reaches a final reading on the basis of individual lexical preferences.

(12) $\mathrm{O}$ adras zestathike.

The-NOM man-NOM warm up-PERF-NON-ACTIVE.3s

"The man warmed up" (preferred reading: unaccusative)

(13) O adras kriftike.

The-NOM man-NOM hide-PERF-NON-ACTIVE-3s

"The man hid" (preferred reading: reflexive)

Overall, on the basis of Tsimpli's (2006) account, the disambiguation of NACT verbs between an unaccusative and a reflexive reading seems to be nonfixed as it is dependent on pragmatic factors as well as on the [ \pm animacy] of the syntactic subject of the verb, while the classification of ACT verbs as unaccusatives is strictly lexically constrained. Animacy appears to be relevant in the processing of ACT unaccusative verbs as well. Several event-related potential studies (Hoeks Stowe, \& Doedens, 2004; Kuperberg, 2007) have found that the co-occurrence of an inanimate subject with a transitive verb results in P600 effect, despite the sentence being syntactically well formed. Such findings evince that animacy and verb types modulate structural choices, with animate entities being preferentially mapped onto subjects/agents and inanimate entities onto objects/themes.

\section{PREDICTIONS OF THE STUDY}

The main prediction of the study pertains to the patients' retained or nonretained sensitivity to the argument structure distinction between unergatives and unaccusatives during on-line sentence processing. If antecedent reactivation is observed on-line only in unaccusatives (and not in unergatives) and at the right point, in the immediate temporal vicinity where it is licensed (i.e., at the gap position), then this pattern would be evidence that the individuals with Broca aphasia comprehend unaccusative constructions normally. If we observe late-occurring effects (i.e., some time after the trace is encountered), then this would suggest that filler-gap dependencies are affected in Broca aphasia, since such protracted effects have already been observed with unaccusatives (e.g., Burkhardt et al., 2003), as well as other sentence types (e.g., Love et al., 2008). Partial support for the aphasic individuals' preserved sensitivity to the silent, postverbal placeholder in unaccusatives receiving its reference from the preverbal subject DP is also the participants' RTs for the trials with a semantically unrelated word at a postverbal position; we 
expected RTs for the unrelated probes (in unaccusatives only) to be considerably higher relative to the unergative verbs on the assumption that "reaction times for the unrelated probes may be treated as an indication for processing load due to gap-filling" (Friedman et al. 2008, p. 15) implicated in unaccusative verbs.

The second prediction made for the aphasic performance in unaccusatives relates to the facilitatory role played by the NACT morphological marking on unaccusative verbs during on-line sentence processing. As already mentioned, besides the ACT-NACT unaccusative verb distinction manipulated in the present study, special status was also assigned to the voice-alternating properties of some Greek unaccusative verbs which can surface with either ACT or NACT voice morphology. We expect that the NACT unaccusative verbs, as well as the ACT unaccusatives that have a marked morphological alternant (i.e., the same verb appearing in NACT voice morphology) will be stronger in their expression of transitivity than the ACT nonvoice-alternating unaccusatives. ${ }^{4}$ The assumption is that whenever a mediopassive suffix is involved (see the Linguistic framework of the study: verb classes [b] and [d] where the Voice ${ }^{\circ}$ projection is fixed and optional, respectively), the aphasic subjects will be able to capture the transitivity alternation more readily by trying to establish a dependency relation between the postverbal gap and the derived subject; this would mean that the relevant structures will be more susceptible to a priming effect (i.e., to postverbal antecedent reactivation) relative to the morphologically unmarked structures (i.e., the ACT nonvoicealternating unaccusatives). Furthermore, we expect that the postverbal argument will be faster reactivated for NACT unaccusatives (assumingly, immediately after the verb where the gap is licensed) relative to the ACT voice-alternating verbs where we expect delayed antecedent reactivation due to the patients' protracted access to the verbs' voice-alternation property. ${ }^{5}$

Conversely, tracking and resolving the filler-gap dependency in ACT nonvoicealternating unaccusative verbs might be more computationally intensive, thus more difficult for the aphasic parser. Perhaps, the latter verb class requires both syntactic reconstruction of the displaced DP, as well as considerations of lexicon-filtered information, and these combine to overwhelm the processing system in aphasia. If this assumption is true, then ACT nonvoice-alternating unaccusatives should yield no antecedent reactivation at a postverbal position at all.

If these predictions on the aphasic performance are verified, then this pattern would be evidence that processing difficulty increases when the aphasic parser is forced to proceed to a morphologically nontransparent action (i.e., parsing the ACT nonvoice-alternating verbs). It would also be partial support for our initial stipulation that unaccusative verbs in Greek (at least) should be further subdivided on the basis of their [ \pm voice-alternation] properties. A necessary condition on these assumptions, however, is the aphasic individuals' increased sensitivity to the morphology of the verbs, which further implicates that the patients should have normal access to the verbs' conceptual representations and could syntactically compute and maintain the NACT alternant along with the ACT one during the on-line processing of ACT voice-alternating unaccusatives.

Finally, the third prediction of the study relates to the [ \pm animacy] of the subject and the way it affects the resolution of both ACT and NACT unaccusative predicates during the processing of the sentences by the patients. As already mentioned, 
inanimate subjects of NACT verbs may only be encountered in derived structures (i.e., unaccusatives, passives and middles). As such, the postverbal reactivation of the antecedent for the inanimate trials for the aphasic group is anticipated to take place regardless of whether the patients have disambiguated the unaccusative meaning of the NACT verb. On the contrary, NACT verbs with an animate subject in Greek can be interpreted either as unaccusatives or reflexives, the two of them being distinguished on the basis of the derived versus nonderived status of their syntactic subject, respectively. The concurrent computation of both a reflexive and an unaccusative derivation is expected to bring about an overall disruption in the patients' on-line processing operations, reflected in a more prominent priming/antecedent reactivation effect (i.e., considerably shorter RTs elicited for the related probes relative to the semantically unrelated probes) for the trials with an inanimate entity relative to the trials with an animate entity in subject position. We anticipate this interpretive ambiguity to be resolved once the reflexive reading is ruled out at a relatively late point in time on the basis of the aphasic individuals' lexical preferences or the disambiguating cues provided by the continuation of the clause.

With respect to ACT unaccusatives, we predict that these verbs with an animate entity in subject position are at high risk of being misinterpreted as unergatives (or as transitives with a null object) by our aphasic population. More specifically, we expect that occasional nonstandard filtering of the syntactic output by the patients' lexicon will distort the idiosyncratic theta grid of the specific verbal set, thus impeding the reconstruction of the displaced DP as originating from the internal object position. The treatment of the preverbal subject DP as an external argument will thus block the postverbal reactivation of the antecedent. If such hypothesis holds true, we expect that the aphasic postverbal priming effect for the ACT unaccusatives with an animate subject will be similar to the priming effect observed for the unergative verbs (also with an animate subject). In other words, we expect no antecedent reactivation to take place postverbally for neither ACT unaccusatives with an animate subject nor unergatives. We return to this, and other implications, in our Discussion to follow our experiment.

\section{METHOD}

\section{Subjects}

Aphasic subjects. A group of eight Greek-speaking agrammatic aphasic subjects (all males, mean age $=69.6$ years, mean years of education $=9.3$ ) participated in the study. The patients were recruited from a Treatment Medical Centre in the Greek province. All subjects were right-handed, with the exception of a single patient who was bimanual. None of the subjects had a history of prior neurological disease, drug or alcohol abuse, psychiatric disorders, developmental speech/language disorders, or learning disabilities. Computed tomography scans, which were available for seven of the patients, revealed that they had suffered from a left hemisphere, ischaemic stroke leaving a deep lesion in the Broca area; one of the patients suffered from an extensive hemorrhage of the left basal ganglia, while two of the patients with an ischaemic stroke have also suffered from a second 
Peristeri et al.: The time course of antecedent reactivation

incident at the same brain area a few years after the first stroke. All subjects were between 1 and 21 years poststroke at the time of the study, while none had received language treatment in the past (see Table 1 for more details on the patients' biographical profile and Appendix A for information on each patient's exact lesion site).

Language testing. The diagnosis of aphasia was based on administration of the Boston Diagnostic Aphasia Examination Third Edition-Short Form (BDAESF; Goodglass, Kaplan, \& Barresi, 2001) standardized in Greek by Tsapkini, Emmanuel, Passalidou, and Nassiopoulou (2007), as well as a series of sentencepicture matching tasks (Peristeri, 2005) that looked at various syntactic structures, including focused and clitic left dislocated sentences, passives, subject and object relative clauses, and reflexives. Leaving aside the individual differences in the aphasia quotients derived from both tests, auditory verbal comprehension, while impaired, was found to be superior to verbal expressive ability. Moreover, results from the sentence-picture matching tasks revealed that comprehension of object relatives, passives and focused sentences was more disrupted than comprehension of reflexives, clitic left dislocated, and subject relative clauses. Furthermore, most of the patients have exhibited low performance in repetition tasks measured at the word and the sentence level. A summary of these results is reported in Table $2^{6}$ and Table 3.

Control subjects. Fifteen language-unimpaired native speakers of Greek (all males) also participated in the study to provide a baseline of healthy performance. Control subjects (mean age $=69.2$ years, mean years of education $=9$ ) were carefully selected to match most closely the mean age and educational level of the aphasic experimental group in order to ensure that any deviation observed between the performance of the controls and the aphasic patients would not be biased by factors such as age and educational level. None of the controls had a history of neurological, psychiatric, or developmental speech, language, or hearing problems.

\section{Materials}

Each participant heard 92 aurally presented sentences consisting of 46 experimental sentences and 46 fillers. The fillers involved diverse syntactic structures consisting of a main clause followed by a causal or a temporal subordinate sentence. The 46 experimental sentences included 16 ACT unaccusative verbs (half [+voice-alternating], and half [-voice-alternating]), 14 unaccusative verbs bearing NACT voice morphology ${ }^{7}$ (half [+voice-alternating], and half [-voicealternating] $)^{8}$ and, finally, 16 unergative verbs (see Appendix B for the full list of the testing sentences). The verbs from all three verb classes were balanced in frequency of occurrence (mean frequency per thousand based on the Institute for Language and Speech Processing Corpus in Greek): unergative 1.43, ACT unacc. 5.6, NACT unacc. 2.1, which did not differ significantly $F(2,43)=1.216, p=$ .307 ; frequency ranges $=0.1-6.80,0.1-49.0$, and 0.1-16.70, and $S D \mathrm{~s}=0.189$, 1.312 , and 4.35 , respectively. All of the antecedents were full DPs and included 
Table 1. Demographic Information of the participants in the Broca group

\begin{tabular}{|c|c|c|c|c|c|c|c|c|}
\hline & \multicolumn{8}{|c|}{ Patient } \\
\hline & $\mathrm{GCH}$ & VSK & SP & THP & DENT & THR & THEX & PAPAL \\
\hline \multicolumn{9}{|l|}{ BDAE-SF severity } \\
\hline Gender & $\mathrm{M}$ & $\mathrm{M}$ & M & $\mathrm{M}$ & $\mathrm{M}$ & M & $\mathrm{M}$ & M \\
\hline Age (years) & 57 & 47 & 68 & 87 & 79 & 74 & 76 & 69 \\
\hline $\begin{array}{l}\text { Time since onset } \\
\text { (years) }\end{array}$ & 3.5 & 4.3 & 20 & 6.1 & 6.1 & $\begin{array}{l}\text { 1st incid. 3.1, } \\
\text { 2nd incid. } 1.1\end{array}$ & $\begin{array}{l}\text { 1st incid. 7.9, } \\
\text { 2nd incid. } 10.9\end{array}$ & 2.2 \\
\hline Hemiparesis & None & $\mathrm{R}$ weakness & $\mathrm{R}$ weakness & $\mathrm{R}$ weakness & $\mathrm{R}$ weakness & $\mathrm{R}$ weakness & $\mathrm{R}$ weakness & $\mathrm{R}$ weakness \\
\hline Education (years) & 12 & 16 & 9 & 4 & 17 & 4 & 7 & 6 \\
\hline Handedness & $\mathrm{R}$ & $\mathrm{R}$ & $\mathrm{R}$ & $\mathrm{R}$ & $\mathrm{R} / \mathrm{L}$ & $\mathrm{R}$ & $\mathrm{R}$ & $\mathrm{R}$ \\
\hline
\end{tabular}

Note: BDAE-SF, Boston Diagnostic Aphasia Examination, Third Edition—Short Form; R, right; L, left. 
Table 2. The eight aphasic patients' individual performances on the BDAE-SF battery

\begin{tabular}{|c|c|c|c|c|c|c|c|c|c|}
\hline $\begin{array}{l}\text { BDAE-SF } \\
\text { Subtests }\end{array}$ & & $\mathrm{GCH}$ & VSK & SP & THP & DENT & THR & THEX & PAPAL \\
\hline \multirow{3}{*}{ Fluency } & Phrase length & $90 \%$ & $90 \%$ & $20 \%$ & $90 \%$ & $90 \%$ & $90 \%$ & $90 \%$ & $20 \%$ \\
\hline & Melodic line & $100 \%$ & $30 \%$ & $20 \%$ & $100 \%$ & $40 \%$ & $80 \%$ & $60 \%$ & $20 \%$ \\
\hline & Grammatical form & $70 \%$ & $60 \%$ & $20 \%$ & $80 \%$ & $50 \%$ & $20 \%$ & $50 \%$ & $20 \%$ \\
\hline Conversation & Simple social responses & $80 \%$ & $80 \%$ & $20 \%$ & $90 \%$ & $80 \%$ & $20 \%$ & $80 \%$ & $50 \%$ \\
\hline \multirow[t]{4}{*}{$\begin{array}{l}\text { Auditory } \\
\text { comprehension }\end{array}$} & Basic word discrimination $(N=16)$ & $\begin{array}{c}12 \\
(75 \%)\end{array}$ & $\begin{array}{c}13.5 \\
(84.3 \%)\end{array}$ & $\begin{array}{c}12.5 \\
(78.1 \%)\end{array}$ & $\begin{array}{c}14 \\
(87.5 \%)\end{array}$ & $\begin{array}{c}11.5 \\
(71.8 \%)\end{array}$ & $\begin{array}{c}10.5 \\
(65.6 \%)\end{array}$ & $\begin{array}{c}14 \\
(87.5 \%)\end{array}$ & $\begin{array}{c}13 \\
(81.2 \%)\end{array}$ \\
\hline & Commands $(N=10)$ & $\begin{array}{c}8 \\
(80 \%)\end{array}$ & $\begin{array}{c}7 \\
(70 \%)\end{array}$ & $\begin{array}{c}4 \\
(40 \%)\end{array}$ & $\begin{array}{c}7 \\
(70 \%)\end{array}$ & $\begin{array}{c}8 \\
(80 \%)\end{array}$ & $\begin{array}{c}5 \\
(50 \%)\end{array}$ & $\begin{array}{c}10 \\
(100 \%)\end{array}$ & $\begin{array}{c}10 \\
(100 \%)\end{array}$ \\
\hline & Complex ideational material $(N=6)$ & $\begin{array}{c}4 \\
(66.6 \%)\end{array}$ & $\begin{array}{c}3 \\
(50 \%)\end{array}$ & $\begin{array}{c}2 \\
(33.3 \%)\end{array}$ & $\begin{array}{c}5 \\
(83.3 \%)\end{array}$ & $\begin{array}{c}1 \\
(16.6 \%)\end{array}$ & $\begin{array}{c}2 \\
(33.3 \%)\end{array}$ & $\begin{array}{c}4 \\
(66.6 \%)\end{array}$ & $\begin{array}{c}5 \\
(83.3 \%)\end{array}$ \\
\hline & Articulatory agility & $30 \%$ & $40 \%$ & $20 \%$ & $60 \%$ & $40 \%$ & $20 \%$ & $60 \%$ & $20 \%$ \\
\hline Recitation & Automatized sequences $(N=4)$ & $\begin{array}{c}4 \\
(100 \%)\end{array}$ & $\begin{array}{c}2 \\
(50 \%)\end{array}$ & $\begin{array}{c}4 \\
(100 \%)\end{array}$ & $\begin{array}{c}4 \\
(100 \%)\end{array}$ & $\begin{array}{c}4 \\
(100 \%)\end{array}$ & $\begin{array}{c}4 \\
(100 \%)\end{array}$ & $\begin{array}{c}4 \\
(100 \%)\end{array}$ & $\begin{array}{c}1 \\
(25 \%)\end{array}$ \\
\hline \multirow[t]{2}{*}{ Repetition } & Words $(N=5)$ & $\begin{array}{c}3 \\
(60 \%)\end{array}$ & $\begin{array}{c}4 \\
(80 \%)\end{array}$ & $\begin{array}{c}4 \\
(80 \%)\end{array}$ & $\begin{array}{c}4 \\
(80 \%)\end{array}$ & $\begin{array}{c}5 \\
(100 \%)\end{array}$ & $\begin{array}{c}5 \\
(100 \%)\end{array}$ & $\begin{array}{c}5 \\
(100 \%)\end{array}$ & $\begin{array}{c}3 \\
(60 \%)\end{array}$ \\
\hline & Sentences $(N=2)$ & 0 & $\begin{array}{c}2 \\
(100 \%)\end{array}$ & 0 & $\begin{array}{c}1 \\
(50 \%)\end{array}$ & $\begin{array}{c}2 \\
(100 \%)\end{array}$ & $\begin{array}{c}2 \\
(100 \%)\end{array}$ & $\begin{array}{c}2 \\
(100 \%)\end{array}$ & $\begin{array}{c}1 \\
(50 \%)\end{array}$ \\
\hline \multirow[t]{3}{*}{ Naming } & Responsive naming $(N=10)$ & $\begin{array}{c}4 \\
(40 \%)\end{array}$ & $\begin{array}{c}6 \\
(60 \%)\end{array}$ & $\begin{array}{c}6 \\
(60 \%)\end{array}$ & $\begin{array}{c}7 \\
(70 \%)\end{array}$ & $\begin{array}{c}4 \\
(40 \%)\end{array}$ & $\begin{array}{c}2 \\
(20 \%)\end{array}$ & $\begin{array}{c}10 \\
(100 \%)\end{array}$ & $\begin{array}{c}9 \\
(90 \%)\end{array}$ \\
\hline & Boston Naming Test ${ }^{a}(N=15)$ & $\begin{array}{c}3 \\
(20 \%)\end{array}$ & $\begin{array}{c}10 \\
(66.6 \%)\end{array}$ & $\begin{array}{c}4 \\
(26.6 \%)\end{array}$ & $\begin{array}{c}9 \\
(60 \%)\end{array}$ & $\begin{array}{c}5 \\
(33.3 \%)\end{array}$ & $\begin{array}{c}9 \\
(60 \%)\end{array}$ & $\begin{array}{c}10 \\
(66.6 \%)\end{array}$ & $\begin{array}{c}3 \\
(20 \%)\end{array}$ \\
\hline & Special categories $(N=12)$ & $\begin{array}{c}9 \\
(75 \%)\end{array}$ & $\begin{array}{c}12 \\
(100 \%)\end{array}$ & $\begin{array}{c}12 \\
(100 \%)\end{array}$ & $\begin{array}{c}10 \\
(83.3 \%)\end{array}$ & $\begin{array}{c}12 \\
(100 \%)\end{array}$ & $\begin{array}{c}11 \\
(91.6 \%)\end{array}$ & $\begin{array}{c}12 \\
(100 \%)\end{array}$ & $\begin{array}{c}12 \\
(100 \%)\end{array}$ \\
\hline
\end{tabular}

Note: BDAE-SF, Boston Diagnostic Aphasia Examination, Third Edition—Short Form.

${ }^{a}$ Second Edition, Short Form (Kaplan, Goodglass, \& Weintraub, 2001). 
Table 3. The eight aphasic patients' accuracy scores in the syntactic comprehension SPMTs (raw data and percentages)

\begin{tabular}{|c|c|c|c|c|c|c|c|c|}
\hline Syntactic Subtests (SPMTs) & $\mathrm{GCH}$ & VSK & SP & THP & DENT & THR & THEX & PAPAL \\
\hline Subject-relative clauses $(N=6)$ & $\begin{array}{c}4 \\
(66.6 \%)\end{array}$ & $\begin{array}{c}4 \\
(66.6 \%)\end{array}$ & $\begin{array}{c}3 \\
(50 \%)\end{array}$ & $\begin{array}{c}5 \\
(83.3 \%)\end{array}$ & $\begin{array}{c}5 \\
(83.3 \%)\end{array}$ & $\begin{array}{c}5 \\
(83.3 \%)\end{array}$ & $\begin{array}{c}5 \\
(83.3 \%)\end{array}$ & $\begin{array}{c}5 \\
(83.3 \%)\end{array}$ \\
\hline Object-relative clauses $(N=6)$ & $\begin{array}{c}4 \\
(66.6 \%)\end{array}$ & $\begin{array}{c}4 \\
(66.6 \%)\end{array}$ & $\begin{array}{c}2 \\
(33.3 \%)\end{array}$ & $\begin{array}{c}4 \\
(66.6 \%)\end{array}$ & $\begin{array}{c}6 \\
(100 \%)\end{array}$ & $\begin{array}{c}2 \\
(33.3 \%)\end{array}$ & $\begin{array}{c}4 \\
(66.6 \%)\end{array}$ & $\begin{array}{c}3 \\
(50 \%)\end{array}$ \\
\hline Focused sentences $(N=20)$ & $\begin{array}{c}14 \\
(70 \%)\end{array}$ & $\begin{array}{c}15 \\
(75 \%)\end{array}$ & $\begin{array}{c}5 \\
(25 \%)\end{array}$ & $\begin{array}{c}11 \\
(55 \%)\end{array}$ & $\begin{array}{c}15 \\
(75 \%)\end{array}$ & $\begin{array}{c}5 \\
(25 \%)\end{array}$ & $\begin{array}{c}15 \\
(75 \%)\end{array}$ & $\begin{array}{c}3 \\
(15 \%)\end{array}$ \\
\hline Clitic left dislocated sentences $(N=8)$ & $\begin{array}{c}8 \\
(100 \%)\end{array}$ & $\begin{array}{c}8 \\
(100 \%)\end{array}$ & $\begin{array}{c}5 \\
(62.5 \%)\end{array}$ & $\begin{array}{c}6 \\
(75 \%)\end{array}$ & $\begin{array}{c}4 \\
(50 \%)\end{array}$ & $\begin{array}{c}6 \\
(75 \%)\end{array}$ & $\begin{array}{c}8 \\
(100 \%)\end{array}$ & $\begin{array}{c}6 \\
(75 \%)\end{array}$ \\
\hline Passive sentences $(N=24)$ & $\begin{array}{c}13 \\
(54.1 \%)\end{array}$ & $\begin{array}{c}12 \\
(50 \%)\end{array}$ & $\begin{array}{c}6 \\
(25 \%)\end{array}$ & $\begin{array}{c}19 \\
(79.1 \%)\end{array}$ & $\begin{array}{c}19 \\
(79.1 \%)\end{array}$ & $\begin{array}{c}9 \\
(37.5 \%)\end{array}$ & $\begin{array}{c}14 \\
(58.3 \%)\end{array}$ & $\begin{array}{c}12 \\
(50 \%)\end{array}$ \\
\hline Reflexive sentences $(N=6)$ & $\begin{array}{c}3 \\
(50 \%)\end{array}$ & $\begin{array}{c}2 \\
(33.3 \%)\end{array}$ & $\begin{array}{c}3 \\
(50 \%)\end{array}$ & $\begin{array}{c}6 \\
(100 \%)\end{array}$ & $\begin{array}{c}3 \\
(50 \%)\end{array}$ & $\begin{array}{c}6 \\
(100 \%)\end{array}$ & $\begin{array}{c}3 \\
(50 \%)\end{array}$ & $\begin{array}{c}3 \\
(50 \%)\end{array}$ \\
\hline Subject-verb agreement $(N=20)$ & $\begin{array}{c}15 \\
(75 \%)\end{array}$ & $\begin{array}{c}19 \\
(95 \%)\end{array}$ & $\begin{array}{c}15 \\
(75 \%)\end{array}$ & $\begin{array}{c}16 \\
(80 \%)\end{array}$ & $\begin{array}{c}18 \\
(90 \%)\end{array}$ & $\begin{array}{c}18 \\
(90 \%)\end{array}$ & $\begin{array}{c}18 \\
(90 \%)\end{array}$ & $\begin{array}{c}18 \\
(90 \%)\end{array}$ \\
\hline
\end{tabular}

Note: SPMTs, sentence picture matching tasks. 
Peristeri et al.: The time course of antecedent reactivation

15 inanimate and 31 animate nouns. More specifically, all syntactic subjects in the unergative sentences were [+animate], seven syntactic subjects in the NACT verb condition were [+animate] and seven were [-animate], and eight syntactic subjects in the ACT unaccusative verb condition were [+animate] and eight were [-animate]. The letter sequences for lexical decision (i.e., the visually presented probes) included 92 words and 46 nonwords.

The nonword probes conformed to Greek orthographic and phonological rules, and appeared with the filler sentences. For the word-probes we created 46 pairs of words; in each pair, one word was related to the head of the subject DP and the other was unrelated. Related probes were close semantic associates of the subject DP, while each unrelated probe was chosen to be matched in number of syllables with the corresponding related probe. Both related and unrelated probe words were balanced in frequency of occurrence (mean frequency per thousand based on the Institute for Language and Speech Processing Corpus in Greek): related $=36.1$, unrelated $=25.4$, which did not differ significantly, $F(1,136)=1.801, p=.182$; frequency ranges $=0-206.9,0-193.7$, and $S D \mathrm{~s}=5.23$ and 3.91, respectively. It is of the most importance that both the related and the unrelated probes were always matched with the [ \pm animacy] feature of the syntactic subject. Each head of subject DP and each probe appeared only once per participant during the entire sentence list.

All of the stimuli were recorded (and digitized at a $48-\mathrm{kHz}$ sampling rate) by a female native speaker of Greek at a normal speaking rate. The stimuli were afterwards broken into three blocks using SoundEdit and entered into E-Prime psychological software to create the CMLP experiment. The experimental and filler sentences were pseudo randomly assigned to positions in a script, such that no more than two of either verb type appeared successively.

As can be seen in (14) to (16) below, the visual targets appeared at three probe positions in each sentence. The location of the first two probe positions was determined on the basis of structural criteria: Probe Position 1 was immediately at the offset of the head of the subject (pregap/base position) and Probe Position 2 immediately at the offset of the verb (i.e., at the point where the trace is licensed). Sentential material was added to the subject DP so that enough time would elapse between the antecedent and the trace to allow for decay in activation from the initial appearance of the subject DP. In light of previous research (e.g., Love \& Swinney, 1996; Onifer \& Swinney, 1981; Swinney, 1979) claiming that at least three syllables (or reading time equal to $1.5 \mathrm{~s}$ ) are typically required to detect antecedent decay in priming, and in accordance to Friedmann et al.'s (2008) experimental design, the syntactic subject in the experimental stimuli of the present study was always followed by a prepositional phrase modifying the noun and a modal adverb, together adding up to five to six words. The number of intervening words between the subject head and the trace in the present experiment was smaller than the number of the intervening words in Friedmann et al.'s experimental design (mean $N=8$ ), but the difference was compensated for by Greek words usually comprising a considerably greater number of syllables than English words. Special attention was given to the sentences so that semantic relatedness of noun phrases across neighboring sentences (i.e., two sentences presented one after the other) 
was avoided to prevent indirect priming effects. Finally, Probe Position 3 (postgap position) allowed for an at least four word spill-over region after the main verb across all three verb type conditions:

(14) unergative verb condition

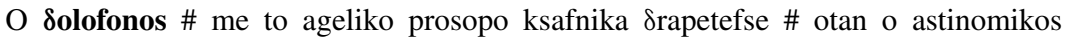
kimithike stin karekla tu tmimatos \# ekso apo to keli

The-NOM murderer-NOM with the-ACC angelical-ACC face-ACC suddenly escapePERF-ACTIVE.3s when the-NOM policeman-NOM fall-PERF-NONACTIVE-3s. (asleep) on the-ACC chair-ACC of the-ACC police station-ACC out of the-ACC cell-ACC

"The murderer with the angelical face suddenly escaped when the policeman fell asleep on the chair of the police station right out of the cell"

Related probe: eglimatias (criminal)

Unrelated probe: poঠosferistis (footballer)

Nonword probe: kepasi

(15) NACT unaccusative verb condition

a. [+animate] subject - [-voice-alternating] condition

$O$ arostos \# me tis lijes meres zois ksafnika jiatreftike \# otan episkeftike ena monastiri prin lijes meres \# ke ekane tama

The-NOM ill man-NOM with the-ACC few-ACC days-ACC life-GEN suddenly healPERF-NONACTIVE.3s when visit-PERF-ACTIVE.3s a-ACC monastery-ACC ago few-ACC days-ACC and make-PERF-ACTIVE.3s offering-ACC

"The ill man with the few days of life suddenly healed when he visited a monastery a few days ago and he made an offering"

Related probe: jiatros (doctor)

Unrelated probe: jata (cat)

Nonword probe: poftokasi

b. [+animate $]$ subject - [+voice-alternating $]$ condition

I nosokoma \# apo ta epijoda ksafnika lerothike \# otan patise se laspes \# se mia lakuva The-NOM nurse-NOM from the-ACC emergency-ACC suddenly spill-PERFNONACTIVE.3s when step-PERF-ACTIVE. $3 \mathrm{~s}$ in mud-ACC in a-ACC pit-ACC

"The nurse from the emergency department suddenly spilled herself when she stepped in the mud of a pit"

Related probe: jiatros (doctor)

Unrelated probe: kota (hen)

Nonword probe: prohi

c. [-animate] subject - [-voice-alternating] condition

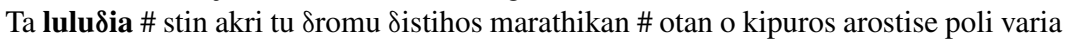
\# ke $\delta$ e $\delta$ ulepse $\delta$ eka mines

The-NOM flowers-NOM in the-ACC corner-ACC the-GEN street-GEN unfortunately wither-PERF-NONACTIVE.3pl when the-NOM gardener-NOM fall-PERFACTIVE.3sg (sick) heavily and not work-PERF-ACTIVE.3sg ten-ACC months-ACC "The flowers in the corner of the street unfortunately withered when the gardener fell heavily sick and did not go to work for ten months"

Related probe: kipos (garden) 
Peristeri et al.: The time course of antecedent reactivation

Unrelated probe: plio (ship)

Nonword probe: krenati

d. [-animate] subject - [+voice-alternating] condition

To harti \# me tis simiosis ksafnika tsalakothike \# otan epese kata lathos kato \# ke to patisame me ta po $\delta i a$

The-NOM paper-NOM with the-ACC notes-ACC suddenly crumple-PERFNONACTIVE.3sg when fall-PERF-ACTIVE.3sg by mistake down and it-CL-ACC step-PERF-ACTIVE.1pl with the-ACC feet-ACC

"The paper with the notes suddenly crumpled when it fell down by mistake and we stepped on it"

Related probe: tertradio (notebook)

Unrelated probe: okeanos (ocean)

Nonword probe: flidaria

(16) ACT unaccusative verb condition

a. [+animate] subject - [-voice-alternating] condition

O trajuסistis \# me tis poles epitihies ksafnika kriose \# otan vjike horis palto \# sto Sromo pu hionize

The-NOM singer-NOM with the-ACC many-ACC hits-ACC suddenly get-PERFACTIVE.3sg (cold) when go-PERF-ACTIVE.3sg (out) without coat-ACC at the-ACC street-ACC where snow-IMPERF-ACTIVE-3sg

"The singer with the many hits suddenly got cold when he went out on the street without a coat while it was snowing"

Related probe: musikos (musician)

Unrelated probe: vasilias (king)

Nonword probe: movivi

b. [+animate $]$ subject - [+voice-alternating] condition

To ajori \# me ta mavra malia ksafnika $\delta$ iplose \# sto e $\delta$ afos apo aforitus ponus \# ke fonaze ti mama tu

The-NOM boy-NOM with the-ACC black hair-ACC suddenly fold-PERFACTIVE.3sg on the-ACC ground-ACC from unbearable-ACC pains-ACC and scream-IMPERF-ACTIVE-3sg the-ACC mother-ACC the-CL-GEN

"The boy with the black hair suddenly folded on the ground with unbearable pains and he was screaming for his mother"

Related probe: koritsi (girl)

Unrelated probe: arahni (spider)

Nonword probe: keruli

c. [-animate] subject - [-voice-alternating] condition

To Sedro \# sto kedro tu kipu ksafnika anthise \# otan o keros ejine kaliteros \# ke anevike i thermokrasia

The-NOM tree-NOM in the-ACC centre-ACC the-GEN garden-GEN suddenly blossom-PERF-ACTIVE.3sg when the-NOM weather-NOM become-PERFACTIVE.3sg better-NOM and rise-PERF-NONACTIVE.3sg the-NOM temperatureNOM

"The tree in the centre of the garden suddenly blossomed when the weather improved and the temperature rose"

Related probe: fila (leaves)

Unrelated probe: stoma (mouth) 
Nonword probe: plogera

d. [-animate] subject - [+voice-alternating] condition

To forema \# me ta pola hromata sinehia tsalakoni \# lojo tis kakis piotitas tu \# opu ki an kathiso

The-NOM dress-NOM with the-ACC many-ACC colours-ACC all the time crinkleIMPERF-ACTIVE.3sg. due the-GEN bad-GEN quality-GEN it-CL-GEN wherever and if sit-PERF-ACTIVE.1sg.

"The dress with the many colours crinkles all the time due to its bad quality wherever I may sit"

Related probe: ifasma (fabric)

Unrelated probe: molivi (pencil)

Nonword probe: sihani

\section{Design and procedure}

In order that no sentence would be heard more than once by the same participant, six scripts comprising the same experimental and filler sentences were created. The three probe positions and the two probe types (related vs. unrelated) for each experimental sentence were then equally distributed across the six scripts. Each participant heard each sentence only once with one of the combinations of probe position and probe type; more specifically, within a single script participants heard 92 sentences (46 experimental sentences, 46 fillers) containing a verb paired with a probe in each of the three probe positions, and for half of each of these the probe was either related to the antecedent DP or unrelated.

All subjects were tested using an Acer laptop computer which was set up on the table at which the subject and the experimenter were seated. The materials were delivered under computer control using the E-Prime experimental package. A computer played a digitized version of the stimuli over loudspeakers at a comfortable listening level. After an initial practice block consisting of 10 filler sentence constructions, the word "READY" appeared on the screen. Using their (poststroke) dominant hand, the aphasic participants pressed the space bar to indicate that they were ready to begin the trial, and the first experimental item was run. During the temporal unfolding of each sentence, a visually presented probe appeared centrally on the screen for an infinite period of time. At that point, subjects were required to make a lexical decision on whether the letter string on the screen was a real word. They were asked to make the decision as quickly and accurately as possible by pressing one of two keys (" 0 " for a nonword, " 1 " for a Greek native word $^{9}$ ).

RTs for the lexical decisions were recorded by E-Prime software and the accuracy of the responses was noted down by the examiner. Shorter RTs on related probes relative to unrelated probes indicate a facilitatory or priming effect. A priming effect is interpreted as resulting from the activation of the head of the subject DP at a specific point in time and it is quantified by subtracting the RT elicited by the semantically related probe from the RT elicited by the semantically unrelated probe per each probe position and per each verb type. Once the lexical decision was made, the subject went through the rest of the aurally presented sentence via the moving time window paradigm. The last word of each sentence 
Peristeri et al.: The time course of antecedent reactivation

was always succeeded by a question mark appearing at the center of the computer screen. At that point (and in $20 \%$ of the experimental trials) the subjects were asked a yes/no comprehension question about the sentence that they had just heard, in order to encourage participants to pay close attention to the meaning of the sentence materials. All six scripts were presented to each participant with a one-week interval between two consecutive scripts.

\section{RESULTS}

Prior to statistical analyses, it was observed that performance was virtually flawless for all of the subjects on those trials $(20 \%)$ that required indicating understanding of the sentence. Thus, the participants were indeed listening to the sentences for meaning. Likewise, all CMLP probes were responded to correctly by all of the participants (i.e., they always pressed " 1 " for the real words and " 0 " for the nonwords), such that no responses were removed from further consideration. Finally, RTs in the CMLP task that exceeded a cut-off point of three standard deviations above or below the mean for each verb type (i.e., unergatives, ACT unaccusatives, NACT unaccusatives) and probe position (Position 1, Position 2, Position 3) were treated as outliers and were replaced by the grand mean for the appropriate condition and for each participant as a conservative measure. Outliers encompassed only $1.63 \%$ of the data for the aphasic group and $4.8 \%$ of the RT data for the controls.

For the sake of clarity of presentation, the findings are presented in four different subsections determined on the basis of the main issue under investigation each time we conducted a statistical analysis of the data: (a) priming effect for the control and the Broca group as a function of probe position and verb class, (b) priming effect for the control and the Broca group as a function of the unaccusative verbs' [ \pm voice-alternation] property, (c) analysis of RTs for the unrelated probe as indication of processing load, and (d) priming effect for the control and the Broca group as a function of the [ \pm animacy] of the syntactic subject.

\section{Priming effect for the control and the Broca group as a function of probe position and verb class}

With the data in the form described above, our first main concern was to look for a priming effect immediately after the subject DP (Probe Position 1), such that the priming effect that would be examined for antecedent reactivation at a postverbal position (Probe Positions $2 \& 3$ ) would not be biased by a possible lexical access or/and integration deficit frequently reported for agrammatic subjects in the aphasiological literature (Blumstein, \& Dworetzky, 1987; Hagoort, 1997; Love et al., 2008; Milberg, Blumstein, \& Dworetsky, 1987; Thompson \& Choy, 2009). A oneway analysis of variance (ANOVA) performed for each subject group with RTs at Probe Position 1 as the dependent factor yielded a significant main effect of probe type across both groups; related probes (1367.3 ms for the controls, $2879.1 \mathrm{~ms}$ for the patients) tended to yield significantly shorter RTs than the unrelated probes (1596.6 ms for the controls, $3833.5 \mathrm{~ms}$ for the patients), $F 1(1,89)=10.616, p<$ .005 for the controls, $F 1(1,47)=4.396, p<.05$ for the patients. The analysis of 
the data with items (sentences) as the random variable $(F 2)$ yielded a significant main effect of probe type for both groups as well; related probes (1373.8 ms for the controls, $2879.6 \mathrm{~ms}$ for the patients) yielded significantly shorter RTs than the unrelated probes (1567.6 ms for the controls, $3878.4 \mathrm{~ms}$ for the patients), $F 2(1,90)=10.911, p<.001$ for the controls, $F 2(1,90)=8.494, p<.005$ for the patients. A between-group analysis of the participants' RT data at Probe Position 1 for each verb category (unergatives, ACT alternating unaccusatives, ACT nonvoice-alternating unaccusatives, NACT alternating unaccusatives, and NACT nonvoice-alternating unaccusatives) revealed significant differences between the aphasic group and the language-unimpaired subjects for almost all verb categories, $F 1(1,21)=6.652, p<.05$ for the unergatives, $F 1(1,21)=6.704$, $p<.05$ for the ACT nonvoice-alternating unaccusatives, $F 1(1,21)=25.294, p<$ .000 for the NACT alternating unaccusatives, and $F 1(1,21)=8.688, p<.01$ for the NACT nonvoice-alternating unaccusatives. This group effect was anticipated since the Broca group exhibited, in general, slower response times relative to the language-unimpaired group.

The statistical analyses of the data consisted of an overall mixed design ANOVA followed by a series of repeated measures ANOVAs aiming at further exploring the significant interaction effects that would result for the various experimental variables of the task. More specifically, the mixed design ANOVA was designed to examine the distinction between the two groups' priming effects at the pregap, gap, and postgap position for each of the verb classes manipulated in the study. Following Friedmann et al.'s (2008) method of data analysis, we then conducted repeated measures ANOVAs focusing on each experimental group separately; what we were mainly interested in the repeated measures ANOVA outputs were the trend analyses for linear and quadratic contrasts that are specifically designed to assess change of the priming effect and the type of the priming effect's change over time for the different verb classes. More specifically, a linear (straight-line) curve would mean that there is a continuous decrease or increase in priming effect from Probe Position 1 to Probe Position 2 and Probe Position 3; this would mean that there is priming for the subject DP and then the antecedent reactivation effect progressively decays or increases as a function of the postverbal domain (Probe Positions $2 \& 3$ ) of the sentence. In contrast, a quadratic trend indicates that a group's priming effect increases at Probe Position 2 and then decays at Probe Position 3 (inverted U-shaped pattern) or decays at Probe Position 2 and then increases at Probe Position 3 (U-shaped pattern). Such curves would translate either into a priming effect immediately after the subject DP and an even stronger antecedent reactivation effect (i.e., an even greater difference between the RTs elicited by the related and the unrelated probes) for the position immediately after the critical verb, or a priming effect at Probe Position 1, decay in activation at the gap position and reactivation of the antecedent at a later point in time (i.e., at Probe Position 3). Preplanned trend analyses were also conducted to examine each group's priming effect trajectories for the animate and the inanimate trials during on-line unaccusative sentence processing.

The mixed-design ANOVA was conducted with group (Broca, controls) as a between-subjects factor, and probe position (pregap, gap, postgap), probe type (related, unrelated), and verb type (unergative, ACT unaccusative, NACT 
Peristeri et al.: The time course of antecedent reactivation

unaccusative) as within-subjects factors. An effect of probe type and verb type were observed, $F 1(1,378)=6.443, p<.01$, and $F 1(2,378)=15.726, p<.000$, respectively, as well as three significant two-way interactions between position and probe, $F 1(2,378)=3.164, p<.04$, probe and group, $F 1(1,378)=3.125$, $p<.05)$, and verb and group, $F 1(2,378)=13.358, p<.000$.

We next conducted separate repeated measures ANOVAs with mean priming effect (lexical decision times to unrelated minus related probes) as within subject factor per each group, per each probe position, per each verb class, as well as per each sentence, per each probe point to search for the source of the aforementioned interactions. The overall mean priming effect for each group, each verb class (unergatives, unaccusatives) and probe position (pregap, gap, postgap) calculated across all data is presented in Table 4 . These are reported here for the subject $(F 1)$ analysis, collapsing over items; the analysis $(F 2)$ collapsing across subjects reveals nearly identical results.

The preplanned trend analyses for the control group with unergative and unaccusative items (sentences) as the random variable, yielded a significant linear trend for the unergative verbs, suggesting that the antecedent was activated at Position 1 , it then decayed and it was not reactivated at a later point in time $(F 2(1,15)=$ $63.420, p<.000)$, and a quadratic trend for the unaccusative verbs, meaning that the antecedent reactivation effect grew stronger at Position 2 and decayed at Position $3(F 2(1,29)=31.002, p<.000)$. With respect to the aphasic group, the trend analysis of their data across the three probe positions yielded a significant linear trend for both the unergative ${ }^{10}$ and the unaccusative verbs $(F 2(1,15)=$ $14.499, p<.005$, and $F 2(1,29)=4.438, p<.05$, respectively).

\section{Priming effect for the control and the Broca group as a function of the unaccusative verbs' [ \pm voice-alternation] property}

Further within-group trend analyses with alternating and nonvoice-alternating unaccusatives as the between-subject factor revealed an effect of the $[ \pm$ voicealternation] dimension on unaccusative sentence processing. More specifically, the analyses for the control group yielded significant quadratic trends for the ACT alternating and NACT nonvoice-alternating unaccusatives, while the quadratic trends for the ACT nonvoice-alternating and NACT alternating unaccusatives were found to be marginally significant, $F 2(1,7)=42.699, p<.000$ for ACT alternating unaccusatives, $F 2(1,7)=5.098, p=.059$ for ACT nonvoice-alternating unaccusatives, $F 2(1,6)=5.110, p=.06$ for NACT alternating unaccusatives, and $F 2(1,6)=16.625, p<.01$ for NACT nonvoice-alternating unaccusatives. In contrast, the ACT nonvoice-alternating unaccusatives for the aphasic group showed a linear trend, $F 2(1,7)=10.039, p<.02$, whereas the NACT unaccusative verb categories yielded marginally significant quadratic trends, indicating a stronger (than Position 1) priming effect at Position 2 and antecedent decay at Probe Position $3, F 2(1,6)=5.196, p=.063$ for NACT alternating unaccusatives, and $F 2(1$, $6)=4.898, p=.069$ for NACT nonvoice-alternating unaccusatives. Of the most interest, the analysis for the ACT alternating unaccusatives also yielded a nearsignificant quadratic trend, $F 2(1,7)=5.042, p=.06$, which was characterized by a U-shaped activation pattern, thus implying that there is priming for the subject 
Table 4. Mean, standard deviation, and range of priming effects (lexical decision time to unrelated minus related probes) for the controls and the Broca group as a function of verb class (unergatives, unaccusatives) and probe position (subject based; F1 analysis)

\begin{tabular}{|c|c|c|c|c|c|c|c|c|c|c|}
\hline \multirow[b]{3}{*}{ Group } & \multirow[b]{3}{*}{ Verb Class } & \multicolumn{9}{|c|}{ Probe Position } \\
\hline & & \multicolumn{3}{|c|}{ Pregap } & \multicolumn{3}{|c|}{ Gap } & \multicolumn{3}{|c|}{ Postgap } \\
\hline & & $M$ & $S D$ & Range & $M$ & $S D$ & Range & $M$ & $S D$ & Range \\
\hline \multirow[t]{2}{*}{ Controls } & Unergatives & $155.1 * *$ & 74.7 & $-66.2-367.4$ & $9.6(n s)$ & 39.1 & $-165.6-187.7$ & $12.6(n s)$ & 10.8 & $-239.6-266.4$ \\
\hline & Unaccusatives & $195.9 * *$ & 460.5 & $30.7-597.5$ & $612.5 * *$ & 361.3 & 213-1015.2 & $7.2(n s)$ & 453.6 & $-359-383.7$ \\
\hline \multirow[t]{2}{*}{ Patients } & Unergatives & $888.9 * *$ & 1509.8 & 225.2-2331 & $-98.2(n s)$ & 162.6 & $-1097.3-900.8$ & $155(n s)$ & 424.5 & $-955.7-1178.3$ \\
\hline & Unaccusatives & $1170.4 * *$ & 1419.2 & $-47.2-3177.1$ & $1548.3(n s)$ & 1482.1 & $-930.5-4292.7$ & $624(n s)$ & 1642.8 & $-1311.6-2813.1$ \\
\hline
\end{tabular}

Note: The statistical significance of priming effects (i.e., significant evidence of antecedent reactivation) is indicated by $* * p<.05$ (significant), *.05 $<$ $p<.07$ (marginally significant), or nonsignificant. 
Peristeri et al.: The time course of antecedent reactivation

DP at Position 1, then decay in activation at the gap position, and then reactivation of the antecedent at Probe Position 3.

An analysis of the RT data with subjects as the random variable $(F 1)$ yielded comparable results. More specifically, repeated measures analyses for the control group, for each of the verb categories yielded a linear trend for the unergatives, $F 1$ $(1,14)=55.782, p<.000$, and a quadratic trend for the rest of the verbal sets, $F 1$ $(1,14)=93.834, p<.000$ for the ACT alternating unaccusatives, $F 1(1,14)=$ 9.802, $p<.01$ for the ACT nonvoice-alternating unaccusatives, $F 1(1,14)=$ 13.007, $p<.01$ for NACT alternating unaccusatives, and $F 1(1,14)=38.547$, $p<.000$ for NACT nonvoice-alternating unaccusatives. In contrast, the analysis for the Broca group yielded a linear trend for the unergatives and the ACT nonvoicealternating unaccusatives, $F 1(1,7)=6.915, p<.04$, and $F 1(1,7)=10.039, p<$ .02 , respectively, and a quadratic trend for the ACT alternating unaccusatives (nearsignificant $p$ value), the NACT alternating and nonvoice-alternating unaccusatives, $F 1(1,7)=5.042, p=.06$ for the ACT alternating unaccusatives, $F 1(1,7)=7.928$, $p<.03$ for the NACT alternating unaccusatives, and $F 1(1,7)=5.819, p<.05$ for the NACT nonvoice-alternating unaccusatives. The overall mean priming effect for each group, each verb type (ACT alternating unaccusatives, ACT nonvoicealternating unaccusatives, NACT alternating unaccusatives, and NACT nonvoicealternating unaccusatives) and probe position (pregap, gap, postgap) calculated across all data is presented in Table 5. These are reported here for the subject $(F 1)$ analysis, collapsing over items (see also Figure 1 for each group's priming trajectories).

A comparison between the verb types at each position for each group, which was done by one-way ANOVAs for each probe position with verb type as the repeated measure yielded different results for the controls and the aphasic group. More specifically, with respect to the controls, the analysis revealed no difference between the verb types for Probe Position $1(p=.54)$ or for Probe Position 3 $(p=.81)$, but yielded a significant effect of verb type for Probe Position 2, F2 (4, $41)=11.407, p<.000$. Further posthoc tests revealed that such effect at Probe Position 2 was derived from significant differences between the unergatives and the rest of the verb types, namely, ACT alternating unaccusatives, $t(7)=4.991$, $p<.001$, ACT nonvoice-alternating unaccusatives, $t(7)=3.678, p<.005$, NACT alternating unaccusatives, $t(6)=3.625, p<.005$, and NACT nonvoice-alternating unaccusatives, $t(6)=6.107, p<.0005$ (one-tailed, item-based data; collapsing across subjects). This supports the pattern of antecedent activation for the five verb types which was found by the trend analyses. In contrast, the analysis for the Broca group revealed no difference between the verb types for Probe Position 1 $(p=.40)$, but yielded a significant effect of verb type for both Probe Positions 2 and $3, F 2(4,41)=12.498, p<.000$, and $F 2(4,41)=2.720, p<.05$, respectively. More specifically, the verb type effect at Position 2 was mainly derived by the significant differences between the NACT unaccusatives (both alternating and nonvoice alternating) and the rest of the verb categories, namely, unergatives and ACT alternating and nonvoice-alternating unaccusatives, $t(6)=5.768, p<.0005$ for the difference between unergatives and NACT alternating unaccusatives, $t(6)=$ $2.848, p<.02$ for the difference between unergatives and NACT nonvoicealternating unaccusatives, $t(6)=4.163, p<.005$ for the difference between ACT 
Peristeri et al.: The time course of antecedent reactivation

Table 5. Mean priming effect (lexical decision time to unrelated minus related probes) and standard deviations for the controls and the Broca group as a function of probe position (pregap, gap, postgap) and the unaccusative verbs' [ \pm voice alternation] property (subject based; F1 analysis)

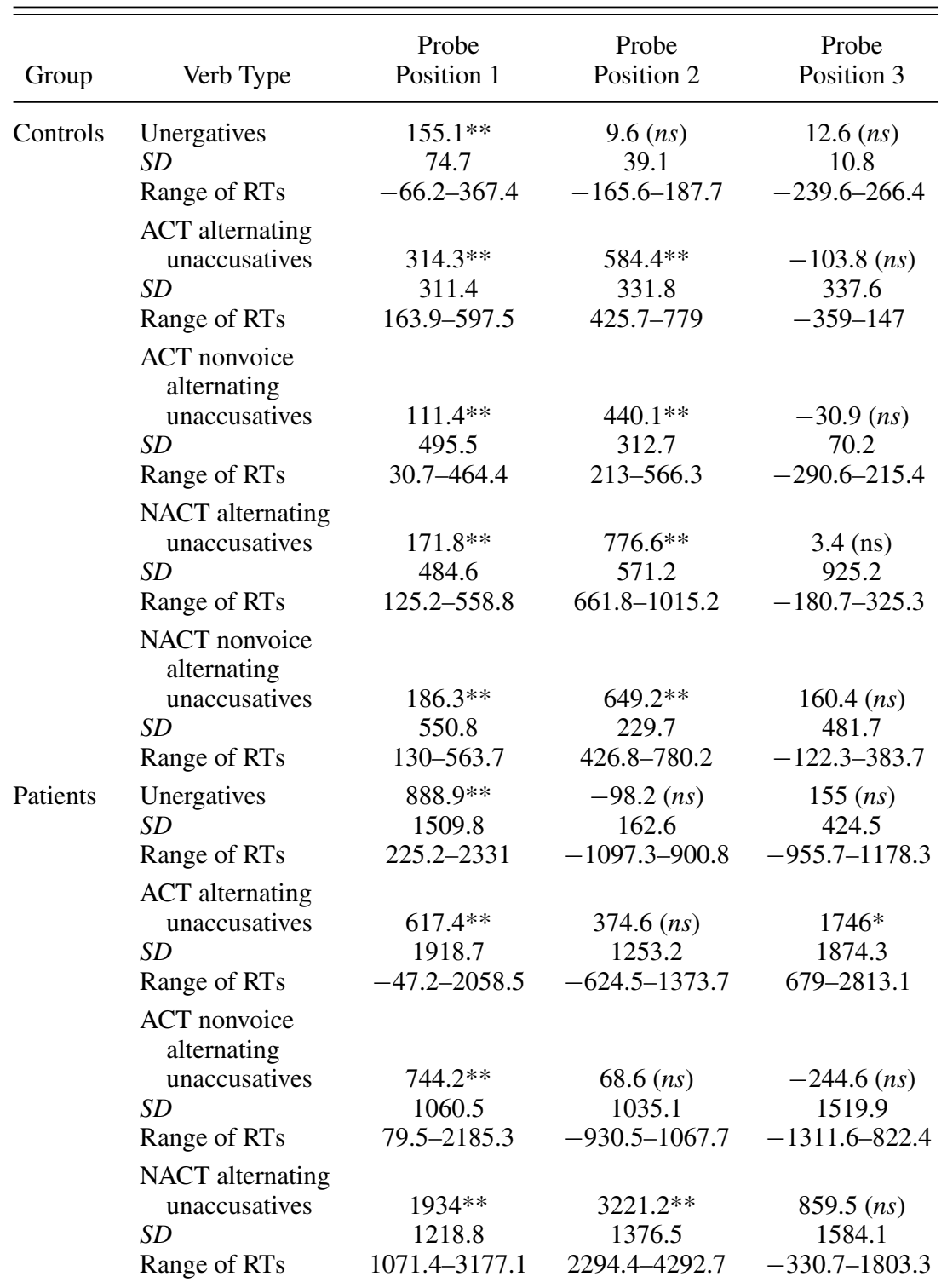


Peristeri et al.: The time course of antecedent reactivation

Table 5 (cont.)

\begin{tabular}{|c|c|c|c|c|}
\hline Group & Verb Type & $\begin{array}{c}\text { Probe } \\
\text { Position } 1\end{array}$ & $\begin{array}{c}\text { Probe } \\
\text { Position } 2\end{array}$ & $\begin{array}{c}\text { Probe } \\
\text { Position } 3\end{array}$ \\
\hline & \multicolumn{4}{|l|}{$\begin{array}{l}\text { NACT nonvoice } \\
\text { alternating }\end{array}$} \\
\hline & $\begin{array}{l}\text { unaccusatives } \\
S D\end{array}$ & $\begin{array}{c}1386.2 * * \\
1479.1\end{array}$ & $\begin{array}{c}2528.9 * * \\
2263.8\end{array}$ & $\begin{array}{c}135.4(n s) \\
1593\end{array}$ \\
\hline & Range of RTs & $612.9-2718.7$ & $1334.6-3332.8$ & $-1060-1074.1$ \\
\hline
\end{tabular}

Note: The statistical significance of priming effects (i.e., significant evidence of antecedent reactivation) is indicated by $* * p<.05$ (significant), ${ }^{*} .05<p<.07$ (marginally significant), or nonsignificant.

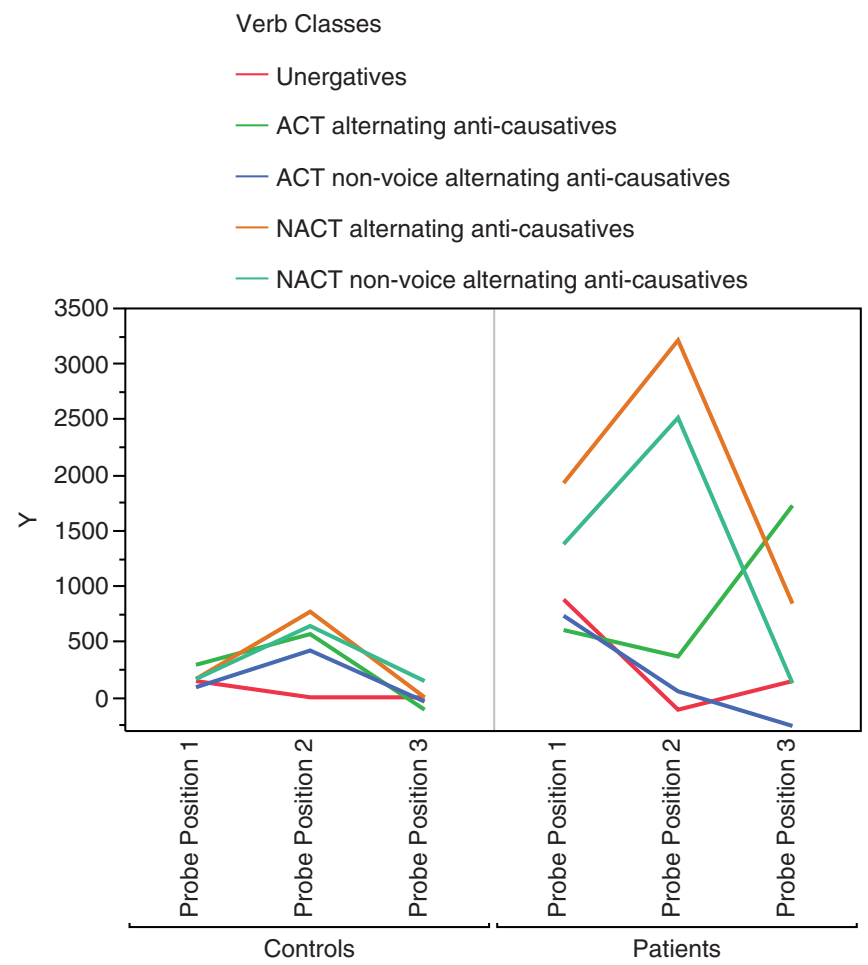

Figure 1. The priming effect (lexical decision time to unrelated minus related probes) for both groups as a function of probe position (pregap, gap, postgap) and verb type (unergatives, active [ACT]-alternating unaccusatives, ACT-nonalternating unaccusatives, nonactive [NACT]alternating unaccusatives, and NACT-nonalternating unaccusatives). 
alternating unaccusatives and NACT alternating unaccusatives, $t(6)=1.768, p<$ .05 for the difference between ACT alternating unaccusatives and NACT nonvoicealternating unaccusatives, $t(6)=3.932, p<.005$ for the difference between ACT nonvoice-alternating unaccusatives and NACT alternating unaccusatives, and $t(6)=2.061, p<.04$ for the difference between ACT nonvoice-alternating unaccusatives and NACT nonvoice-alternating unaccusatives. In contrast, the verb type effect at Probe Position 3 stemmed from significant differences between ACT alternating and nonvoice-alternating unaccusatives, $t(7)=3.069, p<.02$.

\section{Analysis of RTs for the unrelated probe as indication of processing load}

The controls' and the aphasic participants' RT data lent themselves to an additional type of analysis, namely, the measurement of a possible increase in the RTs for the unrelated probes during the priming trajectory from Probe Position 1 to Probe Positions 2, and then to Probe Position 3. To this end, we ran one-way ANOVA analyses for the RTs elicited by the unrelated probe words only, and for each probe position with verb type (unergatives, ACT unaccusatives, NACT unaccusatives) as the repeated measure. With respect to the controls, the analysis revealed no difference between the verb classes for Probe Position 1, but yielded a significant effect of verb class for both Probe Positions 2 and 3, $F 1(2,42)=5.365$, $p<.01$, and, $F 1(2,42)=8.525, p<.001$, respectively. More specifically, the verb type effect at Position 2 was mainly derived by the significant RT difference, $t(14)=3.925, p<.001$ (one-tailed, subject-based data; collapsing across items) detected between the unergatives and the ACT unaccusatives which have yielded the highest RT (for the unrelated probes) among the three verb classes (ACT unaccusatives $=1502.2 \mathrm{~ms}>$ NACT unaccusatives $=1424.1 \mathrm{~ms}>$ unergatives $=$ $1319.2 \mathrm{~ms}$ ). The same pattern of performance was registered for Probe Position 3 , whereby the RT difference between the unergatives and the ACT unaccusatives was found to be statistically significant, $t(14)=5.252, p<.000$, with the highest RTs for the unrelated probes being once more elicited by the ACT unaccusative verb class $($ ACT unaccusatives $=1579.8 \mathrm{~ms}>$ NACT unaccusatives $=1514 \mathrm{~ms}>$ unergatives $=1447.8 \mathrm{~ms}$ ). In contrast, the analysis of the aphasic data for the unrelated probes across the three probe positions has not revealed a significant verb type effect for any of the positions. Yet, it is worth mentioning that the NACT unaccusative verb class tended to systematically yield the highest RTs for the unrelated probes relative to the unergatives and the ACT unaccusatives, with the specific difference becoming more pronounced at Probe Position 2 (NACT unaccusatives $=4717.7 \mathrm{~ms}>$ ACT unaccusatives $=3229 \mathrm{~ms}>$ unergatives $=$ $3049.9 \mathrm{~ms}$ ) and Probe Position 3 (NACT unaccusatives $=4595.5 \mathrm{~ms}>$ ACT unaccusatives $=3396.1 \mathrm{~ms}>$ unergatives $=3315.3 \mathrm{~ms}$ ). Based on the specific data, there was an increase in RTs for the unrelated probes at Probe Position 3 compared to Probe Position 2 for both unergatives and ACT unaccusatives across both the control (increase of $128.6 \mathrm{~ms}$ for unergatives, and $77.6 \mathrm{~ms}$ for ACT unaccusatives) and the aphasic group (increase of $265.4 \mathrm{~ms}$ for unergatives, and 167.1 for ACT unaccusatives). On the contrary, while the controls have exhibited an increase of $89.9 \mathrm{~ms}$ at Probe Position 3 for NACT unaccusatives, the patients have exhibited a decrease of $122.2 \mathrm{~ms}$ for the same verb category. These differences 
Peristeri et al.: The time course of antecedent reactivation

among the three verb classes were not found to be significant on either item $(F 2)$ or subject analysis $(F 1)$.

\section{Priming effect for the control and the Broca group as a function of the [ \pm animacy] of the syntactic subject}

Finally, the manipulation of the [ \pm animacy] feature of the syntactic subject of the verbs across both ACT and NACT unaccusatives in the CMLP task allowed us to evaluate our initial hypothesis that animacy drives syntactic predictions during the processing of the two verb categories. To this end, we ran (a) a comparison between the priming effect elicited by the unergatives (RTs for unrelated probes minus RTs for related probes) and the priming effect elicited by the ACT unaccusatives in the animate trials only (RTs for unrelated, animate probes minus RTs for related, animate probes) at each probe position for each group, which was done by oneway ANOVAs for each probe position with verb type as the repeated measure, and (b) a comparison between the priming effect elicited by the animate trials (RTs for unrelated, animate probes minus RTs for related, animate probes) and that elicited by the inanimate trials (RTs for unrelated, inanimate probes minus RTs for related, inanimate probes) of the NACT unaccusative verb class for each probe position, for each group, which was done by one-way ANOVAs for each probe position with [ \pm animacy] of the subject as the repeated measure.

With respect to the control group, the results from the comparison between the unergatives and the ACT unaccusatives revealed a significant effect of verb type at Probe Position 2: the priming effect for ACT unaccusatives was reliably stronger relative to the unergatives, $F 1(1,28)=3.983, p<.05$, which probably implies that the unaccusative verb subcategorization drove syntactic expectations about argument realization as early as immediately after the verb, thus disregarding animacy violations. In fact, the trend analysis for the animate trials in the ACT unaccusative verb condition, with subjects as the random variable, yielded a significant quadratic trend, $F 1(1,14)=7.604, p<.02$, suggesting that there is priming for the syntactic subject DP, then reactivation of the antecedent at Probe Position 2, and there is no reactivation of the antecedent at a later temporal point. With respect to the aphasic patients, the same analysis yielded no significant difference between the two verb types for neither position; the trend analysis for the animate trials in the ACT unaccusative verb condition has yielded a nonsignificant linear trend $(p=.14)$.

In contrast, the analysis comparing the priming effect between animate and inanimate trials in NACT unaccusatives revealed a significant effect of animacy at Probe Position 2 for both groups; the priming effect for the inanimate trials was found to be considerably stronger relative to the animate trials, $F 1(1,28)=5.219$, $p<.03$ for the controls, $F 1(1,14)=8.769, p<.01$ for the Broca group. More specifically, the trend analyses have yielded significant quadratic effects for the inanimate trials, $F 1(1,14)=11.419, p<.005$ for the controls, $F 1(1,7)=6.535$, $p<.04$ for the patients, indicating reactivation of the antecedent at the gap position and then decay of the priming effect. On the contrary, the trend analyses for the animate trials in the NACT unaccusative verb condition yielded significant for the controls but nonsignificant for the patients U-shaped trends, $F 1(1,14)=16.139$, 
$p<.01$ for the controls, $F 1(1,7)=4.021, p=.08$ for the patients, thus suggesting decay in activation at Probe Position 2, and then reactivation of the antecedent at Probe Position 3.

\section{DISCUSSION}

In this study we have investigated the processing of unaccusativity in a group of patients with Broca aphasia and a group of language-unimpaired control participants by using the CMLP technique. To review, we auditorily presented unergative and unaccusative sentences, the latter appearing with either ACT or NACT voice morphology and with animate or inanimate entities in the syntactic subject position. We presented visual probes either semantically related to the subject-antecedent DP or unrelated probes, and these probes were presented at one of three probe positions: pregap, gap, and postgap sites. With this task, shorter RTs to probes which were semantically related to the derived subject DP, relative to the RTs for the unrelated probes, would indicate activation/priming of the antecedent.

The results indicate distinct priming patterns for the Broca group relative to the language-unimpaired control group, as evinced by significant interactions involving the group variable. The aphasic group evinced no priming at either gap or postgap position for the ACT nonvoice-alternating unaccusative verbs, while late antecedent reactivation (at Probe Position 3) was reported for the patients for the ACT voice-alternating unaccusative verb class. Language-unimpaired controls, in contrast, evinced reactivation of the antecedent immediately at the gap position regardless of the unaccusative verbs' morphological marking (ACT/NACT) or their $[ \pm$ voice-alternation] property. The pattern of aphasic performance suggests that the processing deficit underlying Broca aphasia percolates to their lexiconfiltered system which is responsible for the valuation of some intransitive verbs as unaccusatives in the absence of an overt (NACT) morphological marking on their stem. The late priming effect registered at the postgap position (i.e., at Probe Position 3) for the ACT voice-alternating unaccusatives implies that the possibility of these verbs to appear with NACT voice morphology enhanced the reactivation of the antecedent even in a protracted manner.

A possible explanation for this pattern of performance is that the additional underlying layer of mediopassive morphology in ACT voice-alternating unaccusatives functions as a marker of transitivity and thus facilitates antecedent reactivation, par consequence, grammatical encoding for the specific verb type. The finding that the patients have eventually reactivated the displaced argument at a later temporal window (after the gap site) is probably related to the Broca group's delayed access to the critical verb's underlying NACT morphology. If syntactic structure for ACT unaccusatives must be built at the gap site requiring parallel access to the verb's conceptual representation and lexicon-filtered information, perhaps there was just not enough time for our Broca patients to gain timely access to the verb's voice-alternating property. Probably, the coordination of multiple types of information (i.e., syntactic output, voice morphology, lexicon) in overlapping time spans overwhelms the processing system in Broca aphasia, thus postponing the reconstruction of the missed constituent till a later temporal window once voice morphology cues are fully accessed. This possibility is directly related to accounts 
that speak in favor of an overall slowing down of formal syntactic operations, including the Voice ${ }^{\circ}$ projection, in Broca aphasia (Burkhardt et al., 2003, 2008).

Furthermore, a rather interesting caveat is derived from the patients' antecedent reactivation pattern of performance in ACT voice-alternating unaccusatives. Some of the language comprehension models claiming for a disruption of some process crucial to the comprehension of movement-derived sentences in Broca patients rest on evidence of a reduced verbal working memory capacity. These models (e.g., Martin, 2003; Rogalsky, Matchin, \& Hickok, 2008) posit that verbal working memory functions are associated with activation in the Broca area, such that a trauma to the specific brain region may reduce the efficiency of retrieval mechanisms necessary for restoring information into active memory, thus increasing language difficulties for the aphasic patients. Following the same line of reasoning, voicealternating verbs implicating an additional morphological layer should increase the amount of items that either need to be held in memory or be retrieved during integration processes. The findings of the present study provide evidence in favor of the patients' spared (yet, delayed) access to the NACT morphological alternant of ACT voice-alternating unaccusatives; such morphophonological cue may be held responsible for the presence of a priming effect in the ACT voice-alternating, but not in the ACT nonvoice-alternating unaccusatives.

One possibility for such pattern of performance is that the [+voice-alternation] property of unaccusative verbs is relevant in a separate morphological interface, which computes the morphophonologically distinct voice forms of a single voicealternating verbal root, while a different mechanism computes hierarchical syntactic relations. The idea of a presyntactic morphology interface responsible for the morphological realization of categories retrieved from the lexicon was first introduced by Froud (2001) to account for her aphasic patient's morphological representations of functional categories. Froud conceived of such an interface as an isolable module in the language faculty that feeds into syntax. It is crucial that the morphology interface is not available to top-down interference, thus it is not subject to the memory-based constraints modeling linguistic production and comprehension. We may thus account for the Broca group's ability to gain access to the NACT morphological alternant of ACT voice-alternating unaccusatives in terms of a relatively intact morphological processing stream that is assumingly independent from memory-based limitations. This explanation is also consistent with Caplan and Waters' (1996, 1999), and Waters and Caplan's (2004) theory of working memory as a set of resources that each support different language comprehension functions.

In contrast, the aphasic group's antecedent reactivation pattern in NACT (both alternating \& nonalternating) unaccusative verbs was striking in its similarity to the language-unimpaired subjects; a priming effect was observed immediately after the critical NACT verb at the gap site. Partial support for the distinctive priming behaviour of the NACT unaccusative verb class (relative to the ACT unnacusatives) in the Broca group is also offered by the verb class effect that has emerged at Probe Position 2 and has set apart NACT from ACT unaccusatives in terms of the strength of the two sets' priming effect. The patients' timely establishment of a link between the postverbal trace and its antecedent in real time for NACT unaccusatives validates our previous finding that the NACT 
suffix serves as a substantial morphosyntactic cue to the on-line derivation of the argument structure of the unaccusative verbs. The specific assumption requires that the patients are sensitive to the verbs' morphology, and this sensitivity is probably contingent on the strong interpretability of the NACT morpheme; the morphological marking of the verb after the suppression of the external theta feature indicates a thematic structure/transitivity change. In this sense, the specific finding conflicts with the impaired interpretable features hypothesis which proposes that "functional categories that carry interpretable features cause more difficulties to nonfluent aphasic subjects" (Varlokosta et al., 2006, p. 742) and that for these patients "the morphophonological realisation of interpretable features [is] not functioning" (Nanousi et al., 2006, p. 235). ${ }^{11}$ The facilitatory role of the unaccusative verb's morphological marking on the on-line dependency formation between the postverbal trace and the derived subject position does not appear to emerge in production where morphophonological complexity of inflected verb forms predicts retrieval difficulties for aphasic patients (e.g., Miceli \& Caramazza, 1988).

The patients' processing of unergative verbs, in contrast, offers evidence in favor of the aphasic individuals' sensitivity to the subcategorization information encoded in the specific verb class. Such sensitivity was manifested in the lack of a significant priming effect at either gap or postgap position. Nevertheless, the weak upwards shift of the priming trajectory at Probe Position 3 for the unergatives implies a replanning of the sentence-initial planning window for the patients, and can (carefully) be interpreted as a weak antecedent reactivation effect at the postgap site. Of the most interest, this pattern of performance was encountered in Burkhardt et al.'s (2003) study wherein the unergatives registered a statistically significant priming effect $100 \mathrm{~ms}$ after the verb for the neurologically intact control subjects. As already mentioned, this effect was accounted for in terms of the VP-internal subject hypothesis (Koopman \& Sportiche, 1991).

According to the present study, this finding for the Broca group could be accounted for by different possibilities. One first account may be that the patients' syntactic deficit impeded on their full access and utilization of the subcategorization information of the verbs that were ultimately interpreted by the patients as transitives. Yet, this explanation does not fully account for the priming effect emerging at Probe Position 3 and not immediately after the verb at the gap site. According to the second possibility, the specific pattern could reflect the systematic grammaticalization of transitivity reported for an increasing number of verbs of semitransparent intransitivity in the Greek language (Roussou \& Tsimpli, 2007). There is empirical evidence from Modern Greek showing that lexical transitivization takes place in a specific subclass of unergative/intransitive V-roots (mainly manner of motion and bodily function verbs; some of them are used in the present task, see unergatives in the Appendix B) in which the correlation between unergativity and intransitivity is not absolute. This semitransparency allows for the verbs' causativization, with the ultimate aim of shifting the attentional focus from the causee to the cause of the event portrayed by the verb (e.g., Ta pola

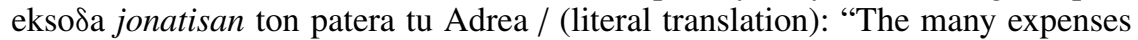

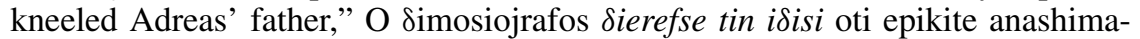
tismos tis kivernisis/"The journalist leaked the news that a Cabinet shuffle is 
Peristeri et al.: The time course of antecedent reactivation

underway," Me afta pu foras pos na se kikloforiso/"How I am supposed to go you out with the clothes that you are wearing?," I Maria etrekse to projrama/"Maria ran the programme"). If this transitivization procedure is underway in the Greek language, we may reason that the priming effect at the postgap site is not due to a disruption of information encoded in the subcategorization restrictions of the unergative verbs in question, but rather to a causativization procedure triggered by discourse-based reasons that raised the patients' expectancy levels for a postverbal object. $^{12}$

Partial insights into the language processing capacities of the Broca group are also gained by its RTs for the unrelated probes across both the unergative and the unaccusative verbs. More specifically, the specific data were treated as an indication of gap filling (Friedman et al., 2008; Shapiro, Gordon, Hack, \& Killackey, 1993; Shapiro, Nagel, \& Levine, 1993; Shapiro, Zurif, \& Grimshaw, $1987 ; 1989)$ such that unmet expectations of an unrelated probe at the gap position (needed to be filled with the antecedent) would result in considerably increased RTs for the relevant trials. The first point to be noted relates to the unexpected finding that the greatest postverbal increase in RTs for the unrelated probes was registered for the unergative verbs at Probe Position 3 across both experimental groups. Although this result was not found to be significant it may carefully be interpreted as evidence in favor of a transitivization effect. More specifically, one viable possibility is that the increase in RTs (for the unrelated probes) reflects the participants' unmet expectations for a postverbal object, like in transitive sentences.

Another point worth mentioning pertains to the finding that the patients' RTs for the unrelated probes were not significantly different across the various verb classes, except maybe from their tendency to slow down their lexical responses for the unrelated probe trials especially in the NACT unaccusative verb condition at both Positions 2 and 3. On the contrary, RTs for the ACT unaccusative verbs for the control group were significantly contrasted with the RTs for the unergatives, with the latter eliciting the shortest RTs during on-line sentence processing. The lack of a parallel effect in the Broca group offers support for our assumption that unergatives and ACT unaccusatives were treated in the same way by the patients. Perhaps, the individuals with aphasia did not exert more effort as the complexity of the linguistic materials increased, as is the case with ACT unaccusatives which require a combinatorial stream of information from both the lexicon and the syntactic output for their resolution. This is consonant with the experimental literature demonstrating that individuals with aphasia have difficulty monitoring their own performance, appropriately evaluating task demands, and thus allocating a sufficient amount of resources for the successful processing of the sentences (Murray, Holland, \& Beeson, 1997; Tseng, McNeil, \& Milenkovic, 1993). In contrast, the overall slowing down of the patients' lexical responses for the NACT unaccusatives at the postverbal region may be attributed to the morphophonological complexity of the mediopassive morpheme; the decomposition of a NACT verb produces more "activity" than the processing of a morphologically less complex form (Tsimpli, 2006). Following this reasoning, a second viable account for the patients' lack of a significant RT difference across the different verb types at the postverbal region is that the processing resources of the individuals with aphasia were taxed 
to the maximum by the NACT unaccusative sentences to begin with, such that, increasing complexity of the ACT unaccusative sentences did not further impact RTs for the unrelated probes.

We end by elaborating on the evidence highlighting the crucial role played by the [ \pm animacy] of the subject in the modulation of the patients' parsing choices for the unaccusative sentences. The lack of a significant postverbal difference between the priming effect elicited by unergatives and ACT unaccusatives with an animate subject in the Broca group evinces that both structures were parsed in a similar manner; there was no reactivation of the antecedent for ACT unaccusatives with an animate entity in subject position. The most plausible explanation for this pattern of performance relates to a heuristic-based strategy of thematic role assignment whereby an animate entity in subject position is a prototypical actor/agent, as such, it best qualifies for an unergative or a transitive parsing scenario. Following the specific heuristics, we hypothesize that the animacy of the subject argument in ACT unaccusatives might have led the aphasic parser to assume an unergative (or a transitive with a null object) interpretation, thus blocking antecedent reactivation postverbally. On the contrary, the controls appeared not to be influenced by the animacy of the subject during the processing of ACT unaccusatives; the difference in the priming effect between the two verb classes (i.e., unergatives vs. ACT unaccusatives) was found to be significant, thus suggesting that a syntactically and lexically determined interpretation construing the subject as originating from an internal argument position in ACT unaccusatives tended to overcome any animacy bias.

The comparison between the priming effects elicited by animate and inanimate subjects in NACT unaccusatives points towards the same interpretive direction, that is, the crucial interference of animacy heuristics during on-line agrammatic sentence processing. More specifically, the postverbal priming effect for the inanimate trials was found to be considerably stronger relative to the animate trials, which have exhibited weak signs of antecedent reactivation at the postgap position. We believe that the U-shaped trajectory of the priming effect in NACT unaccusatives with an animate subject is attributed to a garden-path effect caused by the early interference of the reflexive reading during on-line sentence processing. The reader is reminded that NACT verbs with an animate subject are also prone to a reflexive interpretation (along with the unaccusative one) whereby the single syntactic argument is the verb's true, nonderived agent. The lack of an antecedent reactivation effect at Position 2 for NACT unaccusatives with an animate subject may thus be attributed to the dominance of the reflexive reading, which is a relatively cost-free parsing option relative to the "copy-paste" procedure (that is, the reconstruction of the DP subject at a postverbal position) implicated in unaccusatives. The temporal span available to the patients after the gap has probably allowed them some time to access the verbs' lexical information, yet, it was not enough to attain at significant antecedent reactivation for the relevant verb class at Probe Position 3.

It is crucial that the dissociation between the priming effects elicited by the animate and the inanimate trials in NACT unaccusatives for the Broca group was most pronounced for Probe Position 2 (i.e., the gap site). Such finding implies that the patients gained access to the [士animacy] of the verb's subject immediately 
after the verb. On the contrary, the reader is reminded that the patients' access to the underlying NACT voice morphology for the ACT voice-alternating unaccusative verbs was achieved at a later point during the temporal unfolding of the sentence (i.e., at Probe Position 3). Such pattern of performance is consistent with the observation that Broca patients primarily rely on semantic information in assigning thematic roles to syntactic arguments in general (Saffran, Schwartz, \& Linebarger, 1998).

It is of the most interest that the control group has exhibited similar to the Broca group's patterns of performance across both the animate and the inanimate trials in NACT unaccusatives: a significant priming effect was registered for the inanimate subject trials immediately after the verb, while controls' more robust (relative to the patients) lexical preferences secured a significant priming effect for the animate subject trials as well, yet, in a protracted manner (at Probe Position 3). The particular evidence suggests that the use of heuristics (in other words, a model of parsing that assumes a minimal effort principle for initial parsing) reflects both Broca patients' and language-unimpaired subjects' linguistic system. Such assumption appears to be in line with a number of linguistic and psycholinguistic studies with control populations (e.g., Chang, Bock, \& Goldberg, 2003; Pappert, Zeiske, \& Pechmann, 2009) showing how animacy heuristics are extensively employed during thematic role assignment (especially in morphologically rich languages) in the parsing of noncanonical constructions, as well as in the resolution of syntactic ambiguities. Unfortunately, the use of animacy heuristics has been rarely explored in Broca aphasia; yet, we believe that further and deeper work on the specific issue may eventually lead to a better understanding of language processing in both healthy and impaired populations.

\section{CONCLUSION}

The present study has focused upon investigating Broca patients' sensitivity to the unaccusativity features of intransitive verbs in Greek by using the CMLP technique. Of the most importance, the analyses were also directed to assess which representational type of verb, if any, determined unaccusative verb processing complexity for the patients by manipulating the [ \pm voice-alternation] property of unaccusative verbs in the Greek language. The data from the lefthemisphere damaged subjects show that lexical specification of unaccusativity alone can not account for the patients' processing performance; the patients did not show reactivation of the antecedent for the ACT nonvoice-alternating verbs, while they showed delayed antecedent reactivation for the ACT voice-alternating unaccusatives, thus revealing a protracted reconstruction effect for the latter. This result is in line with previous work suggesting a slow-rise time of syntactically relevant processing routines in agrammatic aphasia, further elucidating Broca patients' difficulty with gaining timely access to the verbs' underlying morphology. In contrast, the NACT verbs were found to be normally reconstructed by the Broca group at the elided position and no later than that. Such evidence suggests that the patients consistently take into account the verbs' (marked) voice morphology during on-line sentence processing. Unlike the patients, the controls did not show 
the asymmetric pattern of NACT > ACT morphology in their priming trajectories, which has been linked to their direct access to the verbs' lexical specifications at the lexicon-syntax interface. It is crucial that the analyses suggest that not only voice morphology cues but also information on the animacy features of the derived subject in unaccusatives is systematically related to the patients' parsing options during on-line unaccusative sentence processing. These data show how together morphological and semantic information facilitates (or hinders) the on-line interpretation of unaccusatives. Experimental materials drawn from languages other than English, thus supplement existing evidence on unaccusativity processing by Broca patients by providing a means of examining the nature of morphology and animacy influences on agrammatic comprehension, and thereby helping to refine accounts of antecedent reactivation patterns in unaccusatives.

\section{APPENDIX A}

Lesion information of each participant in the Broca group

Patient Lesion Site

GCH Left-hemisphere ischemic stroke: lesion in Broca area with deep extension involving cortical and subcortical gyrus of left inferior temporal-parietal lobe and left basal ganglia

VSK Left-hemisphere ischemic stroke: large lesion in Broca area, with deep extension involving subcallosal fasciculus, lesion in insular structure across temporal isthmus, and some superextension to supermarginal gyrus and angular gyrus

SP Extensive hemorrhage of the left basal ganglia: most of Broca area

THP Left-hemisphere ischemic stroke (occlusion of left middle cerebral artery): most of the Broca area, left arcuate fasciculus, anterior and posterior supermarginal gyrus, and part of angular gyrus

DENT Left-hemisphere ischemic stroke: all Broca area, with deep extension to white matter, some involvement of subcallosal fasciculus, insular structure, putamen, anterior limb of internal capsule; superior extension involving lower two-thirds of motor and sensory cortex, anterior and posterior supermarginal gyrus, and part of angular gyrus

THR Left-hemisphere ischemic stroke: patchy left hemisphere lesion involving temporal isthmus and posterior portion of putamen and insular area; posterior supermarginal and angular gyrus areas, with deep extension to border of body of left lateral ventricle

THEX Left-hemisphere ischemic stroke: left frontal Broca area, with deep extension to left frontal horn and lower motor cortex

PAPAL Left-hemisphere ischemic stroke: all Broca area, one-half left arcuate fasciculus, one-half temporal isthmus, one-half Wernicke's area; periventricular white matter, insular structure, putamen, global pallidus, anterior limb of internal capsule, super lesion involving premotor, motor, and sensory cortex, anterior supermarginal gyrus; supplementary motor area, cingulated gyrus area 24 
Peristeri et al.: The time course of antecedent reactivation

\section{APPENDIX B: TESTING SENTENCES}

\section{Unergatives}

1. O jiatros \# me ti lefki po $\delta$ ia ksafnika hamojelase \# otan i omorfi nosokoma \# perase apo to $\delta$ iadromo

"The doctor with the white apron suddenly smiled when the beautiful nurse walked down the corridor"

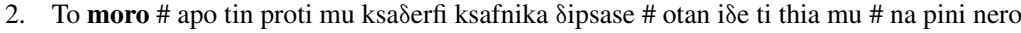
"My first cousin's baby suddenly got thirsty when he saw my aunt drinking water"

3. O thios \# me ti mejali kilia sinehia rohalize \# otan pijene sto krevati \# ke ton eperne o ipnos

"The uncle with the big belly was always snoring when he was going to bed and dozed off"

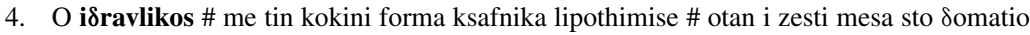
itan foveri \# kai kanena parathiro Sen itan anihto

"The plumper with the red uniform suddenly fainted when the heat in the room was unbearable and no window was open"

5. O psaras \# me to majazi sti jonia ksafnika pinase \# otan i $\delta$ e enan psilo kirio \# na troi mia tiropita

"The fisherman with the shop in the corner suddenly got hungry when he saw a tall man eating a cheese-pie"

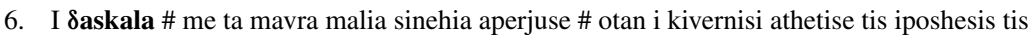

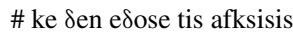

"The teacher with the black hair was continuously on strike when the government didn't keep its promises and didn't grant the raises"

7. O arheolojos \# me to mejalo kapelo ksafnika evikse \# otan i skoni apo ton aera itan poli \# ke bike sto stoma tu

"The archaeologist with the big hat suddenly coughed when the dust from the air got into his mouth"

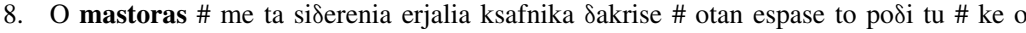
jiatros tu apajorepse na ksana $\delta$ ulepsi

"The craftsman with the iron tools suddenly wept when he broke his leg and the doctor forbade him to work again"

9. O athlitis \# me to htipimeno podi ksafnika ponese \# otan pije na kani jimnastiki \# sto jimnastirio tis jitonias tu

"The athlete with the hurt leg suddenly felt a pain when he tried to exercise at the gym of his neighborhood"

10. O Sikastis \# me to mavro hartofilaka ksafnika etrekse \# otan o katijorumenos gia to fono \# evjale krifa tis hirope $\delta$ es tu

"The judge with the black suitcase suddenly ran when the man who was accused for murder has secretly put out his handcuffs"

11. I nikokira \# me tis poles sakules sta heria vadize \# otan o listis me ti mavri kukula \# tis arpakse me via tin tsada

"The housewife with the many shopping bags on her hands was walking when the thief with the black hood has violently grabbed her bag away"

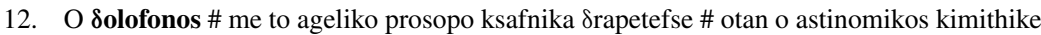
stin karekla tu tmimatos \# ekso apo to keli

"The murderer with the angelical face suddenly escaped when the policeman fell asleep on the chair of the police station right out of the cell"

13. I nifi \# me to makri nifiko sinehia horeve \# otan teliose to fajito tis Seksiosis \# ke ta klarina arhisan 
Peristeri et al.: The time course of antecedent reactivation

"The bride with the long gown was dancing all the time when the dinner of the reception has finished and the clarinets began to play music"

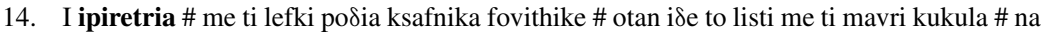
beni sto spiti apo to parathiro

"The maid with the white apron suddenly got scared when she saw the thief with the black hood getting into the house through the window"

15. O enikiastis \# tu Siamerismatos sto Seftero orofo ksafnika efije \# otan pire metathesi stin Athina \# ke anagastike na metakomisi

"The tenant of the apartment on the second floor suddenly left when he got transferred to Athens and he was forced to leave"

16. I mathitria \# tu tritu thraniu ksafnika jelase \# mesa sti mesi tu mathimatos tis istorias \#

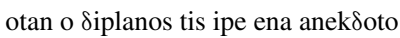

"The student sitting at the third desk suddenly laughed in the middle of the history class when the student next to her cracked a joke"

\section{ACT unaccusatives}

1. O trajudistis \# me tis poles epitihies ksafnika kriose \# otan vjike horis palto \# sto $\delta$ romo pu hionize

"The singer with the many hits suddenly got cold when he went out on the street without a coat while it was snowing"

2. O epihirimatias \# me ta tria erjostasia ksafnika lijise \# otan i trapeza $\delta$ en tu e $\delta$ ose to Sanio \# ke hreokopise

"The businessman with the three factories suddenly bent when the bank didn't grant him the loan and he went bankrupt"

3. I mitera \# me to varia arosto pe $\delta$ i sinehia elione \# kathos etrehe sinehia sta nosokomia \# horis to pe $\delta$ i tis na ginete kala

"The mother with the ill child was wasting way since she kept going to hospitals without her child being healed"

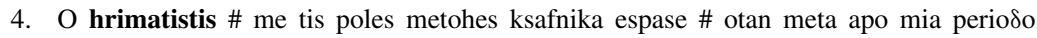
ikonomikis krisis \# emathe oti ehase ola ta ker $\delta$ tu

"The broker with the many stokes suddenly broke when after a period of financial crisis he learnt that he has lost all of his profits"

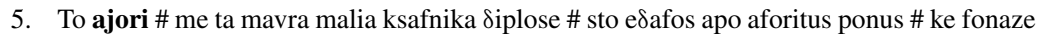
ti mama tu

"The boy with the black hair suddenly folded on the ground with unbearable pains and he was screaming for his mother"

6. To koritsi \# me to roz forema ksafnika htipise \# otan epeze kinijito stin pe $\delta$ iki hara \# ke jlistrise

"The girl with the pink dress suddenly hit when she was playing tag at the playground and she slipped"

7. To moro \# me ta ble matia ksafnika lerose \# mia ora meta to fajito \# otan ekane emeto

"The baby with the blue eyes suddenly spilled himself one hour after lunch when he vomited"

8. To prosopo \# tis ilikıomenis kirias ksafnika tedose \# meta tin triti plastiki epemvasi \# pu ekane to kalokeri

"The face of the old lady suddenly stretched after the third plastic surgery that she had in the summer"

9. To §edro \# sto kedro tu kipu ksafnika anthise \# otan o keros ejine kaliteros \# ke anevike i thermokrasia

"The tree in the centre of the garden suddenly blossomed when the weather improved and the temperature rose" 
Peristeri et al.: The time course of antecedent reactivation

10. I varka \# me ti mejali tripa ksafnika vuliakse \# apo ena megalo kima sti thalasa \# ke pije katefthian ston pato

"The boat with the big hole suddenly sank by a big wave in the sea and it went straight to the bottom"

11. Ta malia mu \# meta ti vafi ksafnika epesan \# otan hrisimopiisa to kenurio proion \# pu iha feri apo Ameriki

"My hair after the tint suddenly fell when I used the new product that I had brought from America"

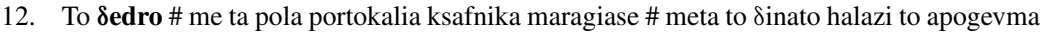
\# ke ola ta fila epesan kato

"The tree with the many oranges suddenly drooped after the strong hail of the afternoon and all its leaves fell down"

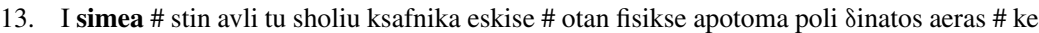
to kodari epese kato

"The flag in the school-yard suddenly tore when a very strong wind blew all of a sudden and the bargepole fell down"

14. To forema \# me ta pola hromata sinehia tsalakoni \# logo tis kakis piotitas tu \# opu ki an kathiso

"The dress with the many colours crinkles all the time due to its bad quality wherever I may sit"

15. To $\delta$ omatio \# sto vorio tmima tu spitiu eftihos zestane \# otan o keros ejine kaliteros \# ke anevike i thermokrasia

"The room at the northern part of the house fortunately heated when the weather improved and the temperature rose"

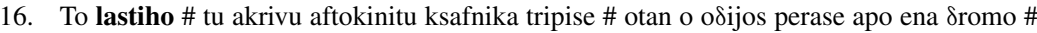
me spasmena jialia

"The tire of the expensive car suddenly pricked when the driver drove on a road with broken glasses"

\section{NACT unaccusatives}

1. I jineka \# me ta makria malia ksafnika zestathike \# otan kathise se ena pagaki tu parku \# ke Sen ihe katholu skia

"The woman with the long hair suddenly heated when she sat on a bench at the park where there was no shadow"

2. To provato \# sti mesi tu dromu ksafnika komatiastike \# otan kapia stijmi htes to apojevma \# perase ena fortijo apo pano tu

"The sheep in the middle of the road was suddenly cut up when some moment yesterday afternoon a truck ran over it"

3. O arostos \# me tis lijes meres zois ksafnika jiatreftike \# otan episkeftike ena monastiri prin lijes meres \# ke ekane tama

"The ill man with the few days of life suddenly healed when he visited a monastery a few days ago and he made an offering"

4. I nosokoma \# apo ta epijoda ksafnika lerothike \# otan patise se laspes \# se mia lakuva "The nurse from the emergency department suddenly spilled herself when she stepped in the mud of a pit"

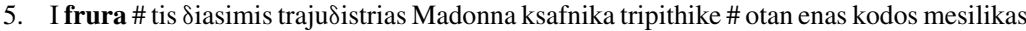
adras \# katafere na plisiasi tin trajuisistria

"The guard of the popular singer Madonna suddenly pricked when a short middle-aged man managed to approach the singer"

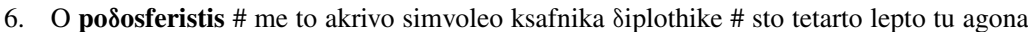
me tin Aglia \# otan o astrajalos tu jirise 
Peristeri et al.: The time course of antecedent reactivation

"The football player with the well-paid contract suddenly folded during the fourth minute of the match with England when his ankle twisted"

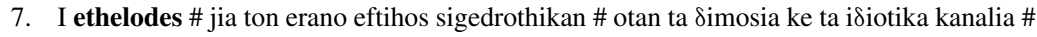
ton Siafimisan me sihna spot

"The volunteers for the fund-raising fortunately assembled when both the public and the private TV channels promoted it with frequent spots"

8. O ilios \# jiro sto apojevma ksafnika kriftike \# otan ta sinefa apo tin katejiða \# plisiasan ke epiase vrohi

"The sun in the afternoon suddenly hid when the clouds from the storm approached and it started to rain"

9. To ptoma \# apo tin ksanthia jineka ksafnika vithistike \# otan to erikse sti thalasa \# o satanikos dolofonos

"The corpse of the blonde woman suddenly sank in the water when the evil murderer threw it into the sea"

10. Ta lulu $\delta$ ia \# stin akri tu $\delta$ romu $\delta$ istihos marathikan \# otan o kipuros arostise poli varia \#

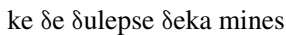

"The flowers in the corner of the street unfortunately withered when the gardener fell heavily sick and did not go to work for ten months"

11. To harti \# me tis simiosis ksafnika tsalakothike \# otan epese kata lathos kato \# ke to patisame me ta posia

"The paper with the notes suddenly crumpled when it fell down by mistake and we stepped on it"

12. To nisi \# sta notia tis Elaðas ksafnika htipithike \# apo ena mejalo sismo jiro sta mesanihta \# ke ta spitia gremistikan

"The island in the south of Greece was suddenly stricken by a huge earthquake around midnight and the houses collapsed"

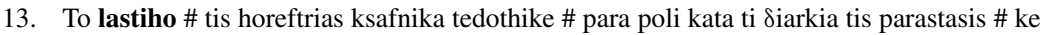
ejine hilia komatia

"The hose of the dancer suddenly stretched too much during the performance and it tore into pieces"

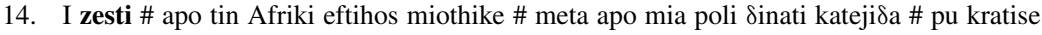
tris ores

"The heat from Africa fortunately faded after a very strong storm that has lasted three hours"

\section{ACKNOWLEDGMENTS}

Many special thanks go to the eight aphasic patients for their contribution to the specific paper, the neurologist Tasos Papapostolou for his valuable help, and the two anonymous reviewers for valuable comments and helpful suggestions.

\section{NOTES}

1. Burkhardt et al.'s (2003) results with respect to the two aphasic subjects' performance on unaccusatives without an underlying causative structure are not clear enough. The authors report that the Broca patients were initially subjected to a task including unaccusative verbs of both types (i.e., with and without an alternative causative structure), but since preliminary results indicated that the patients did not show a clear pattern in unaccusatives without a causative alternant, they decided to do away with these data and concentrate exclusively on unaccusative verbs 
Peristeri et al.: The time course of antecedent reactivation

participating in the causative/inchoative alternation (Burkhardt et al. 2003; subnote 8, p. 17)

2. Note that in Friedmann et al.'s (2008) and Burkhardt et al.'s (2003) studies the term "alternating" for unaccusative verbs is used instead to denote the verbs participating in the causative/inchoative alternation, such as the verb break ("John broke the window"/"The window broke"). In contrast, the "nonalternating" term is used to refer to unaccusatives whose subject never appears as the direct object, such as the verb vanish ("John vanished"/*“"The kidnapper vanished John"). To avoid confusion, we restrict the term "alternating" to the definition offered by Theophanopoulou-Kontou (2000), whereby alternation is understood in terms of the verb's optional change of voice morphology (i.e., ACT/NACT).

3. In the present study, we are not particularly concerned with the exact reading assigned to the NACT verb stimuli used in the task (i.e., whether these verbs are going to be interpreted as unaccusatives, passives or middles). We are mainly interested in the subject in all three aforementioned structures being derived by movement of the object to subject position such that the antecedent should be reactivated at a temporal point postverbally. Nevertheless, we use the term unaccusative for all of the NACT verbs used in the present experiment since they have been labelled as such in the Greek traditional grammar.

4. Likewise, Hale and Keyser (1993) assume that the presence of "additional" morphology in unaccusatives across languages signifies the directionality of the alternation.

5. In contrast, no asymmetry is expected to occur between NACT voice-alternating and nonalternating unaccusative verbs with respect to the priming effect registered at a postverbal position, since the surface NACT morphology is sufficient to signal the transitivity change. As such, we expect that both classes will yield an antecedent reactivation effect at a normal processing moment, that is, immediately after the NACT verb at Probe Position 2.

6. An anonymous reviewer pointed out that the phrase length and repetition performance of some of the patients as assessed by the BDAE-SF battery casts doubts on their diagnosis as Broca aphasic individuals; see Table 2 for six of the patients' (i.e., GCH, VSK, THP, DENT, THR, and THEX) phrase length scores (90\%) and half of the patients (i.e., VSK, DENT, THR, and THEX) sentence repetition scores (100\% accuracy). An analysis of the six individuals' transcribed spontaneous speech and picture description data was first conducted in order to determine the exact content of the "longest possible noninterrupted sequence of lexical items uttered at call" (BDAESF: Goodglass, Kaplan, \& Barresi, 2001, p. 3) by each of these patients during the two subtrials of the BDAE-SF. The analysis revealed that the patients' speech consisted mainly of nouns and rarely articles and adverbs, while the $90 \%$ phrase length score corresponded to five-word utterances at most. We cite a characteristic sample of one of the six patients" (GCH's) description of the "Cookie Theft" picture: [ . . o enas sto

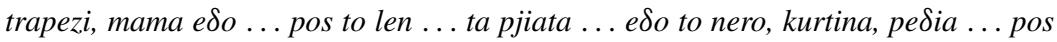
to len ... vrisi, Literal translation: “... the one on the table, mother here ... what is it called ... the plates ... here the water, curtain, children ... what is it called ... tap"]. Such speech data may still be interpreted as indicative of nonfluent speech, since the reduced production of verbs and the overuse of nouns are two basic characteristics of agrammatic speech output (Miceli et al. 1984; Zingeser \& Berndt, 1990). In contrast, the four patients' sentence repetition scores in the BDAE-SF were derived from the 
repetition of two sentences, namely, (a) o pateras erhete spiti/“The father comes home," and (b) perni to harti apo to trapezi/"He takes the paper from the table." As one can see, both sentences are simple transitive structures with commonly used lexical items, such that their accurate repetition may not represent a reliable index of the patients' true repetition capacities. The six patients' repetition scores in the sentence repetition section of the Bilingual Aphasia Test (Paradis, 1987) consisting of frames of varying syntactic complexity, like passives, focused and clitic left dislocated sentences, showed that their repetition performance was near chance level. Under this view, the BDAE-SF may be less sensitive in its use of sentential stimuli to determine the severity of impairment in Broca patients' sentence repetition capacities (Peristeri \& Tsapkini, 2011).

7. Two NACT unaccusative verbs, namely, stejnothike/dry-PERF-NONACTIVE and zarothike/crinkle-PERF-NONACTIVE, were excluded from the testing materials becasue they have received very low acceptability rates in the norming study which was ran to measure verb acceptability, $t(31)=2.120, p<.001$, and $t(31)=2.007$, $p<.003$, respectively.

8. The ACT [+voice-alternating] unaccusatives were siplono (fold-ACT), htipao (hit$\mathrm{ACT}$ ), lerono (spill-ACT), tedono (stretch-ACT), tsalakono (crinkle-ACT), zesteno (heat-ACT), tripao (prick-ACT), skizo (tear-ACT), while the ACT [-voice-alternating] unaccusatives were: kriono (get cold-ACT), lijizo (bend-ACT), liono (melt-ACT), spao (break-ACT), anthizo (blossom-ACT), vuliazo (sink-ACT), pefto (fall-ACT), maragiazo (wither-ACT). The NACT [+voice-alternating] unaccusatives were: zestenome (heat-NACT), leronome (spill-NACT), siplonome (fold-NACT), tripieme (prick-NACT), tsalakonome (crumple-NACT), htipieme (hit-NACT), tedonome (stretch-NACT), while the NACT [-voice-alternating] unaccusatives were: komatiazome (cut up-NACT), jiatrevome (heal-NACT), sigedronome (assemble-NACT), krivome (hide-NACT), marenome (wither-NACT), mionome (fade-NACT), vithizome (sink-NACT).

9. The RTs which were of interest for the statistical analysis were these yielded by pressing the " 1 " button.

10. It is crucial that the patients' priming trajectory in the unergative verb condition slightly curved upwards at Probe Position $3(p=.03)$ relative to the trajectory of the control group whose amount of curvature between Probe Positions 2 and 3 was found to be not significant $(p=.730)$. The specific pattern of reactivation for the aphasic group has yielded a significant, although weaker relative to the linear trend, quadratic trend effect, $F 2(1,15)=13.794, p<.005$.

11. It would be interesting to see whether Wernicke patients' performance in tasks testing argument to role mappings would also be facilitated by strong interpretable cues, like the NACT suffix. The present study predicts that Wernicke patients would fail to exploit such cues because posterior-lesioned patients show patterns of semantic impairment, and the processing of interpretable features is likely to rely on routines more aligned with semantic operations. We are planning to replicate the CMLP experiment with a group of Wernicke patients in the near future.

12. Partial support in favor of the transitivization account is also offered by the individual analysis of the control participants' RT data; the response times obtained for three control subjects in the unergative verb condition registered a statistically significant priming effect immediately after the verb (i.e., at Probe Position 2). 
Peristeri et al.: The time course of antecedent reactivation

\section{REFERENCES}

Alexiadou, A., \& Anagnostopoulou, E. (2004). Voice morphology in the causative-inchoative alternation: Evidence for a non-unified structural analysis of unaccusatives. In A. Alexiadou, E. Anagnostopoulou, \& M. Everaert (Eds.), The unaccusativity puzzle. Oxford: Oxford University Press.

Balaguer, R. D., Costa, A., Sebastian-Galles, N., Juncadella, M., \& Caramazza, A. (2004). Regular and irregular morphology and its relationship with agrammatism: Evidence from two SpanishCatalan bilinguals. Brain and Language, 91, 212-222.

Balogh, J., Zurif, E. B., Prather, P., Swinney, D., \& Finkel, L. (1998). Gap filling and end of sentence effects in real-time language processing: Implications for modeling sentence comprehension in aphasia. Brain and Language, 61, 169-182.

Bird, H., Lambon Ralph, M. A., Seidenberg, M. S., McClelland, J. L., \& Patterson, K. (2003). Deficits in phonology and past-tense morphology: What's the connection? Journal of Memory and Language, 48, 502-526.

Blumstein, S. E., Byma, G., Kurowski, K., Hourihan, J., Brown, T., \& Hutchison, A. (1998). On-line processing of filler-gap constructions in aphasia. Brain and Language, 61, 149-168.

Burkhardt, P., Piñango, M., \& Wong, K. (2003). The Role of the anterior left hemisphere in real-time sentence comprehension: Evidence from split intransitivity. Brain and Language, 86, 9-22.

Burkhardt, P., Avrutin, S., Piñango, M. M., \& Ruigendijk, E. (2008). Slower-than-normal syntactic processing in agrammatic Broca aphasia: Evidence from Dutch. Journal of Neurolinguistics, $21,120-137$.

Burzio, L. (1986). Italian syntax: A government-binding approach. Dordrecht: Reidel.

Caplan, D., \& Waters, G. S. (1996). Syntactic processing in sentence comprehension under dual-task conditions in aphasic patients. Language and Cognitive Processes, 11, 525-551.

Caplan, D., \& Waters, G. S. (1999). Verbal working memory and sentence comprehension. Behavioral and Brain Sciences, 22, 77-94.

Chang, F., Bock, K., \& Goldberg, A. (2003). Do thematic roles leave traces of their places? Cognition, 90, 29-49.

Dickey, M. W., \& Thompson, C. K. (2004). The resolution and recovery of filler-gap dependencies in aphasia: Evidence from on-line anomaly detection. Brain and Language, 88, 108-127.

Friederici, A. D., Wessels, J. M. I., Emmorey, K., \& Bellugi, U. (1992). Sensitivity to inflectional morphology in aphasia: A real-time processing perspective. Brain and Language, 43, 747-763.

Friedmann, N., Taranto, G., Shapiro, L. P., \& Swinney, D. (2008). The leaf fell (the leaf): The online processing of unaccusatives. Linguistic Inquiry, 39, 355-377.

Froud, K. (2001). Linguistic theory and language pathology: Evidence for the morphology interface from a case of acquired language disorder. Unpublished $\mathrm{PhD}$ dissertation, University College London.

Goodglass, H., Kaplan, E., \& Barresi, B. (2001). The assessment of aphasia and related disorders (3rd ed.). Philadelphia, PA: Lippincott Williams \& Wilkins.

Grodzinsky, Y. (1990). Theoretical perspectives on language disorders. Cambridge, MA: MIT Press.

Grodzinsky, Y. (1995). Trace deletion, $\theta$-roles, and cognitive strategies. Brain and Language, 50, 469-497.

Grodzinsky, Y. (2000). The neurology of syntax: Language use without Broca's area. Behavioral and Brain Sciences, 23, 1-71.

Grodzinsky, Y., Piñango, M., Zurif, E., \& Drai, D. (1999). The critical role of group studies in neuropsychology: Comprehension regularities in Broca's aphasia. Brain and Language, 67, 134-147.

Haarmann, H. J., \& Kolk, H. H. J. (1991). Syntactic priming in Broca's aphasics: Evidence for slow activation. Aphasiology, 5, 247-263.

Hagiwara, H. (1993). Comprehension of passive in Japanese aphasics. Brain and Language, 45, 247263.

Hagoort, P. (1997). Semantic priming in Broca's aphasics at shortV SOA: No support for an automatic semantic access deficit. Brain and Language, 56, 287-300.

Hale, K., \& Keyser, S. J. (1993). On argument structure and the lexical expression of grammatical relations. In K. Hale \& S. J. Keyser (Ed.), Essays in honor of Sylvain Bromberger. The view from building 20. Cambridge, MA: MIT Press.

Hoeks, J. C. J., Stowe, L. A., \& Doedens, G. (2004). Seeing words in context: The interaction of lexical and sentence level information during reading. Cognitive Brain Research, 19, 59-73. 
Peristeri et al.: The time course of antecedent reactivation

Kaplan, E., Goodglass, H., \& Weintraub, S. (2001). Boston Naming Test (2nd ed.). Philadelphia, PA: Lippincott Williams \& Wilkins.

Koopman, H., \& Sportiche, D. (1991). The position of subjects. Lingua, 85, 211-258.

Kuperberg, G. R. (2007). Neural mechanisms of language comprehension: Challenges to syntax. Brain Research, 1146, 23-49.

Linebarger, M., Schwarz, M., \& Saffran, E. (1983). Sensitivity to grammatical structures in so-called agrammatic aphasics. Cognition, 11, 361-392.

Levin, B., \& Rappaport-Hovav, M. (1995). Unaccusativity: At the syntax-lexical semantics interface. Cambridge, MA: MIT Press.

Love, T., \& Swinney, D. (1996). Coreference processing and levels of analysis in object-relative constructions: Demonstration of antecedent reactivation with the cross-modal priming paradigm. Journal of Psycholinguistic Research, 25, 5-24.

Love, T., Swinney, D., Walenski, M., \& Zurif, E. (2008). How left inferior frontal cortex participates in syntactic processing: Evidence from aphasia. Brain and Language, 107, 203-219.

Love, T., Swinney, D., \& Zurif, E. (2001). Aphasia and the time-course of processing long distance dependencies. Brain and Language, 79, 169-170.

Luzzatti, C., Raggi, R., Zonca, G., Pistarini, C., Contardi, A., \& Pinna, G. D. (2002). Verb-noun double dissociations in aphasic lexical impairments: The role of word frequency and imageability. Brain and Language, 81, 432-444.

Manzini, M. R., \& Roussou, A. (2000). A minimalist theory of A-movement and control. Lingua, 110, 409-447.

Marslen-Wilson, W. D., \& Tyler, L. K. (1997). Dissociating types of mental computation. Nature, 387, 592-594.

Martin, R. (2003). Language processing: Functional organization and neuroanatomical basis. Annual Review of Psychology, 54, 55-89.

McKoon, G., \& Ratcliff, R. (1994). Sentential context and on-line lexical decision tasks. Journal of Experimental Psychology: Lanquage, Memory, and Cognition, 20, 1239-1243.

Miceli, G., \& Caramazza, A. (1988). Dissociation of inflectional and derivational morphology. Brain and Language, 35, 24-65.

Miceli, G., Silveri, M. C., Villa, G., \& Caramazza, A. (1984). On the basis for the agrammatics' difficulty in producing main verbs. Cortex, 20, 207-20.

Milberg, W. P., Blumstein, S. E., \& Dworetzky, B. (1987). Processing of lexical ambiguities in aphasia. Brain and Language, 31, 138-150.

Murray, L., Holland, A., \& Beeson, P. M. (1997). Accuracy monitoring and task demand evaluation in aphasia. Aphasiology, 11, 401-414.

Nagel, H. N., Shapiro, L. P., \& Nawy, R. (1994) Prosody and the processing of filler-gap sentences. Journal of Psycholinguistic Research, 23, 473-485.

Nanousi, V., Masterson, J., Druks, J., \& Atkinson, M. (2006). Interpretable vs. uninterpretable features: Evidence from six Greek speaking agrammatic patients. Journal of Neurolinguistics, 19, 209238.

Onifer, W., \& Swinney, D. A. (1981). Accessing lexical ambiguities during sentence comprehension: Effects of frequency of meaning and contextual bias. Memory and Cognition, 9, 225-236.

Pappert, S., Zeiske, M., \& Pechmann, T. (2009). Structural priming across verb types and voice. Oral presentation at the 22nd annual CUNY Conference on Human Sentence Processing.

Paradis, M. (1987). The assessment of bilingual aphasia. Hilldale, NJ: Erlbaum.

Penke, M., Janssen, U., \& Krause, M (1999). The representation of inflectional morphology: Evidence from Broca aphasia. Brain and Language, 68, 225-232.

Peristeri, E. (2005). Agrammatism in modern Greek: Aspects of production and comprehension. In E. Agathopoulou, M. Dimitrakopoulou, \& D. Papadopoulou (Eds.), 17th International Symposium: Selected papers on theoretical and applied linguistics (Vol. 2). Thessaloniki: Monohromia.

Peristeri, E., \& Tsapkini, K. (2011). A comparison of the BAT and BDAE-SF batteries in determining the linguistic ability in Greek-speaking patients with Broca aphasia. Clinical Linguistics and Phonetics, 25, 464-479.

Perlmutter, D. M. (1978). Impersonal passives and the unaccusative hypothesis. In J. J. Jaeger, A. E. Woodbury, F. Ackerman, C. Chiarello, O. D. Gensler, J. Kingston, et al. (Eds.), Proceedings of the Fourth Annual Meeting of the Berkeley Linguistics Society. Berkeley, CA: University of California, Berkeley Linguistics Society. 
Peristeri et al.: The time course of antecedent reactivation

Rogalsky, C., Matchin, W., \& Hickok, G. (2008). Broca's area, sentence comprehension, and working memory: An fMRI study. Frontiers in Human Neuroscience, 2, 1-13.

Roussou, A., \& Tsimpli, I. M. (2007). The role of cliticization in Modern Greek. In A. Alexiadou (Ed.), Studies in the morpho-syntax of Greek. Newcastle upon Tyne: Cambridge Scholars Publishing.

Saffran, E. M., Schwartz, M. F., \& Linebarger, M. C. (1998). Semantic influences on thematic role assignment: Evidence from normals and aphasics. Brain and Language, 62, 255-297.

Schwartz, M. F., Linebarger, M. C., Saffran, E. M., \& Pate, D. (1987). Syntactic transparency and sentence interpretation in aphasia. Language and Cognitive Processes, 2, 85-113.

Shapiro, L. P., Gordon, B., Hack, N., \& Killakey, J. (1993). Verb-argument structure processing in complex sentences in Broca's and Wernicke's aphasia. Brain and Language, 45, 423-447.

Shapiro, L., Nagel, N., \& Levine, B. (1993). Preferences for a verb's complements and their use in sentence processing. Journal of Memory and Language, 32, 96-114.

Shapiro, L., Zurif, E., \& Grimshaw, J. (1987). Sentence processing and the mental representation of verbs. Cognition, 27, 219-246.

Shapiro, L., Zurif, E. B., \& Grimshaw, J. (1989). Verb processing during sentence comprehension: Contextual impenetrability. Journal of Psycholinguistic Research, 18, 223-243.

Swinney, D. (1979). Lexical access during sentence comprehension: (Re) consideration of context effects. Journal of Verbal Learning and Verbal Behavior, 18, 645-659.

Swinney, D., Ford, M., Frauenfelder, U., \& Bresnan, J. (1987). The time course of coindexation during sentence comprehension. Paper presented at the Psychonomic Society Meeting, Seattle.

Swinney, D., Zurif, E. B., Prather, P., \& Love, T. (1996). Neurological distribution of processing resources underlying language comprehension. Journal of Cognitive Neuroscience, 8, 174184.

Theophanopoulou-Kontou, D. (2000). -O/-me alternations in MG patient oriented constructions: Anticausatives and passives. In T. Pavlidou \& C. Tzitzilis (Eds.), Proceedings of the 20th Annual Meeting of the Linguistics Department of the University of Thessaloniki. Thessaloniki: University of Thessaloniki.

Theophanopoulou-Kontou, D. (2001). The structure of VP and the mediopassive morphology: The passives and anticausatives in Modern Greek. Oral presentation at the Workshop on Greek Syntax and the Minimalist Seduction, Reading University.

Thompson, C. K. (2003). Unaccusative verb production in agrammatic aphasia: The argument structure complexity hypothesis. Journal of Neurolinguistics, 16, 151-167.

Thompson, C. K., \& Choy, J. J. (2009). Pronominal resolution and gap filling in agrammatic aphasia: Evidence from eye movements. Journal of Psycholinguistic Research, 38, 255-283.

Tsapkini, K., Emmanuel, A., Passalidou, C., \& Nassiopoulou, G. (2007). Boston diagnostic Aphasia examination-short form: Greek normative data. Poster presented at the 9th European Conference on Psychological Assessment (ECPA9), Thessaloniki.

Tsapkini, K., Jarema, G. \& Kehaya, E. (2002). Regularity revisited: Evidence from lexical access of verbs and nouns in Greek. Brain and Language, 81, 103-119.

Tseng, H., McNeil, M. R., \& Milenkovic, P. (1993). An investigation of attention allocation deficits in aphasia. Brain and Language, 45, 276-296.

Tsimpli, I.-M. (2006). The acquisition of voice and transitivity alternations in Greek as a native and second language. In S. Unshworth, T. Parodi, A. Sorace, \& M. Young-Scholten (Eds.), Paths of development in L1 and L2 acquisition. Amsterdam: John Benjamins.

Ullman, M. T., Corkin, S., Coppola, M., Hickok, G., Growdon, J. H., Koroshetz, W. J., et al. (1997). A neural dissociation within language: Evidence that the mental dictionary is part of declarative memory, and that grammatical rules are processed by the procedural system. Journal of Cognitive Neuroscience, 9, 266-276.

Varlokosta, S., Valeonti, N., Kakavoulia, M., Lazaridou, M., Economou, A., \& Protopapas, A. (2006). The breakdown of functional categories in Greek aphasia: evidence from agreement, tense, and aspect. Aphasiology, 20, 723-743.

Waters, G. S., Caplan, D. (2004). Verbal working memory and on-line syntactic processing: Evidence from self-paced listening. Journal of Experimental Psychology, 57, 129-163.

Zingeser, L. B., \& Bemdt, R. S. (1990). Retrieval of nouns and verbs in agrammatism and anomia. Brain and Language, 39, 14-32.

Zurif, E., Swinney, D., Prather, P., Solomon, J., \& Bushell, C. (1993). An on-line analysis of syntactic processing in Broca's and Wernicke's aphasia. Brain and Language, 45, 448-464. 